\title{
A scoping review of interventions for crop postharvest loss reduction in sub-Saharan Africa and South Asia
}

\author{
Tanya Stathers ${ }^{1} \bowtie$, Deirdre Holcroft ${ }^{2,3}$, Lisa Kitinoja ${ }^{3}$, Brighton M. Mvumi ${ }^{4}{ }^{4}$, Alicia English ${ }^{5,10}$, \\ Oluwatoba Omotilewa ${ }^{6}$, Megan Kocher ${ }^{7}{ }^{7}$, Jessica Ault ${ }^{8}$ and Maximo Torero ${ }^{9}$
}

Reducing postharvest losses (PHLs) of food crops is a critical component of sustainably increasing agricultural productivity. Many PHL reduction interventions have been tested, but synthesized information to support evidence-based investments and policy is scarce. In this study, PHL reduction interventions for $\mathbf{2 2}$ crops across $\mathbf{5 7}$ countries in sub-Saharan Africa and South Asia from the 1970s to 2019 were systematically reviewed. Screening of the 12,907 studies identified resulted in a collection of 334 studies, which were used to synthesize the evidence and construct an online open-access database, searchable by crop, country, postharvest activity and intervention type. Storage technology interventions mainly targeting farmers dominated (83\% of the studies). Maize was the most studied crop (25\%). India had the most studies (32\%), while 25 countries had no studies. This analysis indicates an urgent need for a systematic assessment of interventions across the entire value chain over multiple seasons and sites, targeting stakeholders beyond farmers. The lack of studies on training, finance, infrastructure, policy and market interventions highlights the need for interventions beyond technologies or handling practice changes. Additionally, more studies are needed connecting the impact of PHL reductions to social, economic and environmental outcomes related to Sustainable Development Goals. This analysis provides decision makers with data for informed policy formulation and prioritization of investments in PHL reduction.

T he global population is projected to reach 9.7 billion people by $2050^{1}$. This will require a $60 \%$ increase in global food production compared with 2005-2007 levels, alongside more equitable access ${ }^{2}$. Additionally, over 815 million people are chronically undernourished ${ }^{3}$, especially in parts of sub-Saharan Africa (SSA) and South Asia, where $22.8 \%$ and $14.7 \%$ of the overall populations are undernourished, respectively ${ }^{4}$. Postharvest loss (PHL) of food crops, during or after harvest, is a loss of valuable food and of the inputs required to produce and distribute it ${ }^{5}$. Given its substantial scale, reducing PHL will help create more sustainable and resilient food systems, and reduce greenhouse gas emissions. PHL reduction can simultaneously optimize agricultural productivity and increase the incomes of small-scale food producers and associated value-chain actors, especially women, who are traditionally responsible for many postharvest activities.

The causes of PHL and the stages at which they occur are numerous and varied depending on the supply chain, the location and a variety of other contexts. Damage or loss can occur during all postharvest stages. For example, part of the crop may get left behind unharvested in the field, spilt during transportation or attacked by pests or microbes during storage. All of these can reduce the quantity or quality of food available and the associated income opportunities for small-scale food producers. Many of these are preventable through proper training, the adoption of appropriate tools or technologies, effective handling practices, sound policies and marketing-related improvements.

After the food crises of the 1970s and 2007-2008, PHL reduction received more attention and investment. However, due to factors such as poor coordination, inappropriate scale, a focus predominantly on technologies, short-term time frames and lack of follow-up, the investment impact has been limited. Moreover, the failure to invest in proper support for training, institutionalization and services (for example, financial credit, supply chains and distribution networks, quality standards, and improved infrastructure) has contributed to the lack of progress ${ }^{5-13}$.

Targets have been set under Sustainable Development Goal (SDG) 12.3 to reduce losses along the supply chain ${ }^{14}$. African Union Member States have gone even further, pledging to halve postharvest food loss by 2025 under the Malabo Declaration ${ }^{15}$. The reduction of postharvest food loss has wider implications for other SDGs related to food systems, as well as socio-economic and environmental effects related to SDGs $1,2,5,6,7,8,9,10,11,13,14,15$ and $17^{16}$. The critical role of PHL reduction to support the attainment of SDG 2 and the need to review existing evidence were recognized during a consultative exercise coordinated by the Global Donor Platform for Rural Development and the Ceres2030 project (https:// ceres2030.org/). A synthesis of the expanding body of research and development work on interventions that can help small-scale

\footnotetext{
'Natural Resources Institute (NRI), University of Greenwich, Chatham, UK. ${ }^{2}$ Holcroft Postharvest Consulting, Lectoure, France. ${ }^{3}$ The Postharvest Education Foundation, La Pine, OR, USA. ${ }^{4}$ Department of Agricultural and Biosystems Engineering \& Soil Science and Environment, University of Zimbabwe, Harare, Zimbabwe. ${ }^{5}$ Economic and Social Statistics Division, Food and Agriculture Organisation of the United Nations, Rome, Italy. ${ }^{6}$ Microeconomic, Institutional and Development Impact Division, African Development Bank, Abidjan, Cote d'Ivoire. ${ }^{7}$ Magrath Library, University of Minnesota, St. Paul, MN, USA. ${ }^{8}$ National Agricultural Library, Beltsville, MD, USA. ${ }^{9}$ Economic and Social Development Department, Food and Agriculture Organisation of the United Nations, Rome, Italy. ${ }^{10}$ Present address: RaboResearch Food and Agribusiness, Utrecht, The Netherlands. $\varpi_{e}$-mail: t.e.stathers@gre.ac.uk
} 
producers and associated value-chain actors to reduce PHLs is vital for evidence-based decision-making.

\section{Results}

Only 334 of the 12,907 studies (2.6\%) identified for the 22 food crops across 57 countries of SSA and South Asia met the inclusion criteria (Box 1 and Extended Data Fig. 1).

Outline of the evidence. The 334 included studies came from a wide range of sources, with the majority (85.9\%) being journal papers. The earliest articles were published in 1971, and $42.2 \%$ were published in the past decade (Fig. 1a). India accounted for $32.2 \%$ of the articles, while for 25 countries there were no studies that met the inclusion criteria (Fig. 1b and Extended Data Fig. 2). Studies on maize dominated (24.9\%) (Fig. 1c), and, when aggregated by crop group, legumes were the least studied $(7.8 \%)$ (Fig. 1d). When grouped by postharvest activity stages, studies on storage interventions for dry and fresh forms of the crops dominated, each accounting for $42.5 \%$ and $40.1 \%$ of the studies, respectively (Fig. 1e). Most of the studies (91.0\%) focused on postharvest interventions that small-scale producers could use to reduce losses. Studies of loss-reduction interventions for use by traders, transporters or other food-system actors were limited. On-farm/field trials made up $34.1 \%$ of the studies. Surveys accounted for $8.1 \%$, and $57.8 \%$ were research station trials. More detailed descriptive statistics of the evidence can be found in Supplementary Box 1.

Overview of postharvest interventions studied. Cereals had attracted the most study of PHL reduction interventions (43.3\%), particularly maize (25.8\%) (Fig. 2). Root and tuber crops followed (19.9\%), principally potato in India. Next were fruits (19.2\%), particularly citrus and mango in India. The vegetable interventions $(10.7 \%)$ focused on onion or tomato, mainly in India. Legumes had the fewest interventions studied (6.8\%).

Geographically, SSA accounted for $55.0 \%$ of the interventions studied. The most interventions had been studied in India (34.6\%), with a focus on potato, citrus, onion, mango, rice, wheat, banana and tomato. Within SSA, $54.9 \%$ of the interventions were on cereals, $19.9 \%$ on root and tuber crops, $11.5 \%$ on legumes, $7.5 \%$ on fruits and $6.2 \%$ on vegetables.

The PHL reduction interventions studied were aggregated using a four-tier hierarchical system, with the first tier being the intervention type (technology/tool/equipment, handling practice change, training/extension, finance, policy, markets, support or infrastructure). The second tier was the intervention stage, grouped into typical postharvest stages (such as harvesting, drying and storage), and tier 3 was the specific interventions (such as zero-energy cool chamber or traditional granary plus synthetic chemical; for the full list, see Supplementary Table 3). The details of each intervention were provided in tier 4 (for example, the name and application rate of the agricultural chemical or the size of the box).

The analysis of the 334 studies by intervention type (tier 1) highlights the dominance of studies on tangible technologies, tools or equipment ( $88.3 \%$ of studies, $89.0 \%$ of interventions). There were far fewer studies on handling practices $(14.1 \%, 10.5 \%)$, training $(0.6 \%, 0.3 \%)$ and infrastructure $(0.3 \%, 0.1 \%)$. None were on policy, finance, markets or support/organization (Fig. 3).

Measurement of PHL. PHLs are multidimensional and can be measured in different ways, both quantitatively (physical loss) and qualitatively (for example, increased damage, decay, breakage, contamination with toxins, reduced seed viability and deterioration in the nutrient content or economic value of a product $)^{5,16}$. These losses can be assessed using a range of metrics depending on the focus of the research or intended use of the crop. For each intervention

\section{Box 1 | Overview of methods}

Searches. A search strategy was developed in May 2019 and used to sequentially search CAB Abstracts, Web of Science, Scopus and 47 additional electronic database and grey literature sources. The 14,576 records identified were deduplicated, resulting in 12,786 documents for title and abstract screening. A second search was done on 30 October 2019 to ensure that the evidence-base was as current as possible, yielding 121 additional studies.

Study exclusion criteria. Studies were excluded if they:

- Did not include a PHL reduction intervention for one of the 22 focal food crops

- Did not take place in SSA or South Asia

- Were not relevant to PHL reduction by small-scale producers or their associated value-chain actors

- Did not include original research and sufficient details on it

- Did not report the effect of an intervention on PHL, which required comparison between different interventions, between adopters and non-adopters or between pre- and post-adoption

- Did not test an intervention at a meaningful scale at the field level or in a real-world context

- Were not written in either English or French

No date restrictions were applied.

Title and abstract screening. The titles and abstracts were auto-coded by semantic machine-learning models and prescreened using filters and a Python script to expedite the exclusion of studies not related to the focal crops or geographies. The title and abstract of each of the 12,907 studies were then screened independently by two of the postharvest researchers.

Full-text article screening. The 1,906 studies included during the title and abstract screening stage were read to determine whether to include them in the evidence-base. A flow chart of the number of studies and exclusion reasons is shown in Extended Data Fig. 1, and the included studies are listed in Supplementary Table 1.

Data extraction and synthesis. Data from the 334 included studies were extracted into an SQL database version of the coding framework (Supplementary Table 2). Meta-analyses were conducted at both the study and the intervention levels to provide an overview of what interventions have been studied by crop, country and postharvest stage, and to compare the efficacy of the different interventions in reducing PHLs. The searchable SQL database was created to facilitate interactive exploration of the data and is available at https://PHCeres2030.net/.

The systematic method that we followed aims to capture and rigorously screen all the relevant literature to fully explore, map and compare the existing evidence and to identify gaps and reduce authorial bias. The full details of the methodology are provided in the Methods, and the preregistered protocol is available at https://osf.io/6zc92/.

studied, data for one quantitative and one qualitative loss metric were included depending on the evidence presented in the respective study. To support the comparative efficacy analyses, the different loss measurements were aggregated into groups (Supplementary Tables 4 and 5).

PHL reduction interventions and their efficacy. Most of the interventions studied were tangible technologies for reducing losses 
during storage, while a few studies focused on changes in handling practices or training (Fig. 3). A comparison of the loss in quantity or quality for the different interventions can provide an overview of their efficacy. Since the studies were conducted in different years, seasons, locations and contexts and using different varieties by different research teams, comparisons beyond those within a single study provide only an indication of the relative efficacy of the different interventions.

Cereals. For cereals, the focus was primarily on storage technology interventions (Fig. 3), including pesticides (both synthetic chemicals and botanicals), modified atmospheres, storage containers and combinations of these technologies (Supplementary Table 6). Only 11 of the 121 cereal storage studies (9\%) targeted traders or other storage service providers. Six of these studied large-scale storage interventions, such as metal silos or hermetic cocoons of seven-tonne capacity or above, or large bag stacks in warehouses.

Studies on changes in handling practices focused on harvest maturity, timing or weather conditions and their combination with other postharvest handling practices. Some studies evaluated the effects of sorting or field-drying methods.

Simple tools or machines for harvesting were compared with manual practices. Drying technologies studied included different structures and heat sources, as well as protecting the crop from contact with the ground during sun-drying versus drying it directly on the ground. Threshing, shelling or de-husking studies compared manual methods, simple tools and mechanized threshing. Only four studies investigated different milling equipment, all on rice in Ghana, India or Bangladesh. Just one study investigated the effect of farmer training, and that was nearly 50 years ago ${ }^{17}$.

Maize. For the analysis of quantity loss for different maize storage interventions (tier 3), percentage weight loss data were used. For quality loss, the percentage of damaged or discoloured grains was used, although many other quality loss measurements were recorded in the maize studies (Supplementary Table 5). As the studies presented loss data from different storage durations (ranging from 1 to 12 months), the data for a standardized storage period of six months were used to facilitate comparison. Of the 78 studies on maize storage methods, 74 were from SSA and 4 were from South Asia (India and Nepal). The storage method included details of both the facility in which the crop was stored and the protectant used. The heterogeneity between the studies and the small number of cases (that is, $n=1$ or 2 ) for many of the interventions must be noted.

The aggregated data indicated that several air-tight/hermetic facilities, the admixture of grain with diatomaceous earth (DE) or cooking oils, and a fumigated and insecticide-sprayed bag stack kept quantity loss below $2 \%$ during six months of storage (Fig. 4a). Quantity losses ranged widely in maize grain and cobs treated with synthetic chemical protectants and stored in different facilities for six months (that is, from $<1$ to $27 \%$ weight loss), although means from a low $n$ value should be interpreted with caution. Differences in the types, efficacy, stability and application rates of synthetic chemicals, varietal susceptibility, environmental conditions and number of occurrences of the interventions help explain the high variability. For example, the most studied intervention, 'polypropylene bag + synthetic chemical' $(n=21)$, had a weight loss of $7.2 \% \pm 11.2 \%$ (mean \pm s.d.). When the losses in quality between interventions were compared, similar trends to those for the quantity loss data were observed (Fig. 4b). Because much of the grain damage was due to insect pest attack in storage, the relationship between quantity and quality loss was expected. For example, 20\% storage-insect-damaged maize grain typically equates to $5 \%$ weight loss ${ }^{18}$.

Two studies found that mass trapping, biological control agents or synthetic chemicals in traditional granaries lowered weight loss by $13.0-57.6$ percentage points, compared with the traditional practice or an untreated control (Supplementary Fig. 1a,b). Treating fumigated or non-fumigated grain with a residual synthetic chemical dust and storing it in sacks, or storing untreated grain in hermetic bags or metal or plastic silos, lowered weight loss by 1.3-10.1 percentage points and reduced grain damage.

One handling practice study found that selecting cobs with tightly closed husks, as opposed to open husks, reduced insect infestation from $20.0 \%$ to $1.0 \%$. Another study found that improved admixing of protectants with grain reduced storage insect damage from $14.0 \%$ to $3.2 \%$. Proper crop drying, store hygiene, store disinfestation and regular inspection led to lower losses. Cobs field-dried on plants (as opposed to heaped on the ground) and those harvested at physiological maturity (as opposed to several weeks later) experienced lower weight loss and aflatoxin levels (Supplementary Table 7).

Wheat, rice and sorghum. Storage method intervention studies on wheat, rice and sorghum tended to report the percentage of damaged grain $(n=108)$ rather than grain weight loss $(n=66)$.

During wheat storage, a range of pesticide treatments were studied, including repeated fumigation and pesticide spraying of bag stacks, which kept weight loss below 2\% (Extended Data Fig. 3a), as did underground pit storage in India. If products such as industrial filter cake dusts, silicon-rich botanical powder or synthetic chemicals were admixed with grain, or if grain was stored in sealed drums, hermetic bags, concrete bins or improved granaries, weight loss also remained below $2 \%$ at six months and grain damage was below 5\% (Extended Data Fig. 3a,b). When storage interventions were compared with the traditional practice or untreated control, the admixture of synthetic chemical or filter-cake dust or silicon-rich botanical treatments, or storage in sealed plastic containers or hermetic bags, most effectively prevented grain damage (Supplementary Fig. 2a,b). All the wheat storage studies were from South Asia, except one study from Ethiopia.

Less than $2 \%$ weight loss and less than $6 \%$ damage occurred during six months of storage when paddy rice was sealed untreated in hermetic bags, metal silos or improved granaries, or when it was fumigated and stored inside a metal silo or pesticide-incorporated bag (Extended Data Fig. 3a,b). However, when paddy rice was stored untreated in jute or polypropylene sacks, traditional granaries or heaps on a floor, weight losses between $2.8 \%$ and $21.8 \%$ and grain damage between $16.4 \%$ and $20.3 \%$ occurred. When storage interventions were compared with the traditional practice or untreated control, hermetic cocoons, metal silos, traditional granaries with fumigation and rodent control, hermetic bags, and improved granaries lowered weight losses (1.8-5.3 percentage points) and grain damage (12.7-16.4 percentage points) (Supplementary Fig. 2a,b).

Sorghum lost less than $2 \%$ weight during six months of storage when kept untreated in hermetic bags or improved underground pits, in bags following fumigation and admixture with synthetic chemicals, or in a traditional granary admixed with wood ash. Even without these interventions, weight loss was relatively low (2.1-6.9\%) (Extended Data Fig. 3a). Less than 5\% damage occurred when sorghum was fumigated, treated with synthetic chemicals, and stored in bags; or admixed with wood ash, synthetic chemicals or DE and stored in a traditional granary; or stored untreated in hermetic bags or an improved granary. However, untreated grain stored in bags or traditional granaries with or without botanical preparations sustained between $14.1 \%$ and $43.2 \%$ damage (Extended Data Fig. 3b).

Harvesting rice at the recommended time resulted in lower weight loss $(0.6 \%)$ and fewer broken grains $(9.4 \%)$ than either earlier or later harvesting (5.9-20.3\% weight loss and 24.0-32.4\% broken grains) (Supplementary Table 7). Threshing and sun or 
a Distribution of included studies by publication year

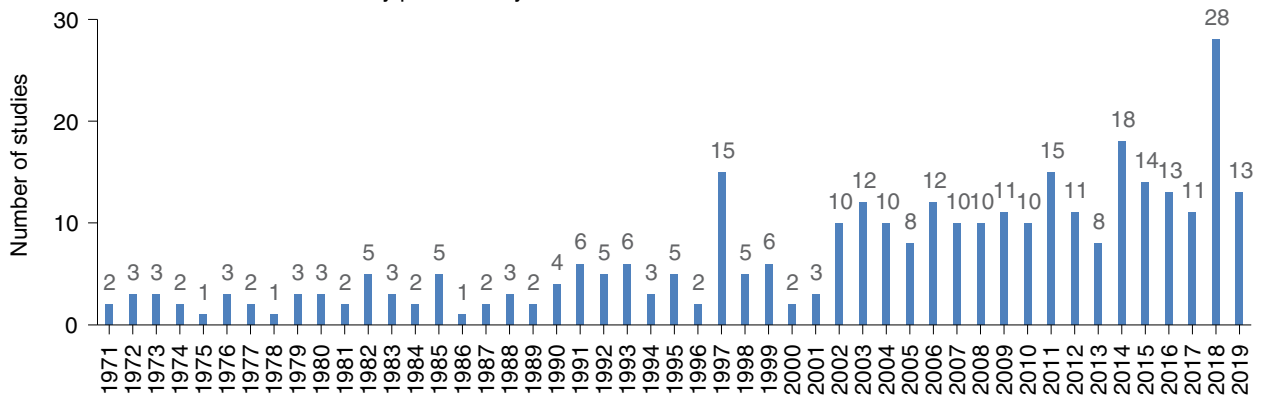

b Distribution of included studies by country

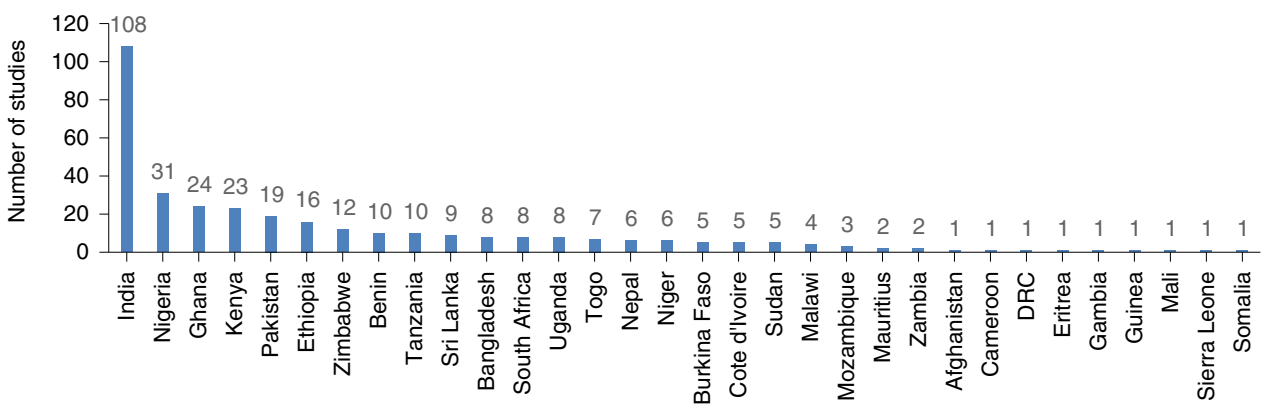

c Distribution of included studies by crop

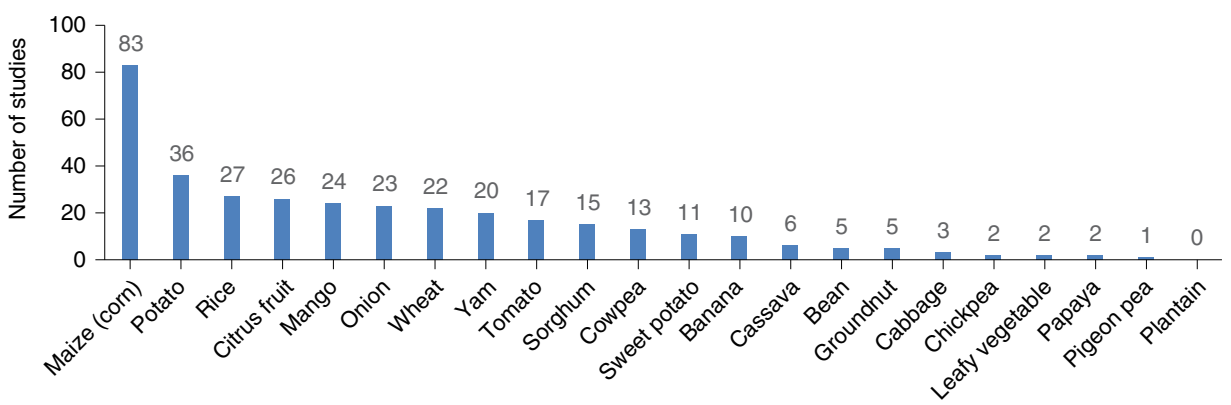

d Distribution of included studies by crop group

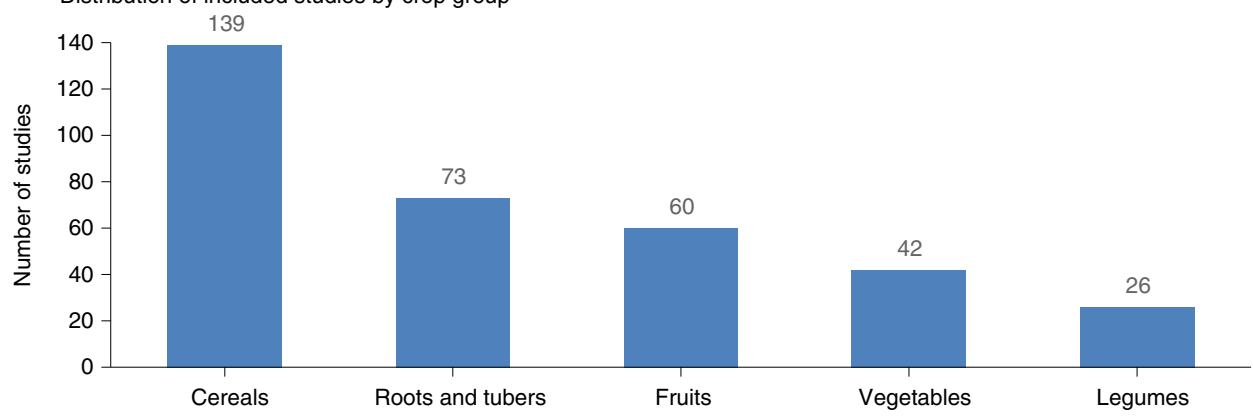

e Distribution of included studies by postharvest activity stage

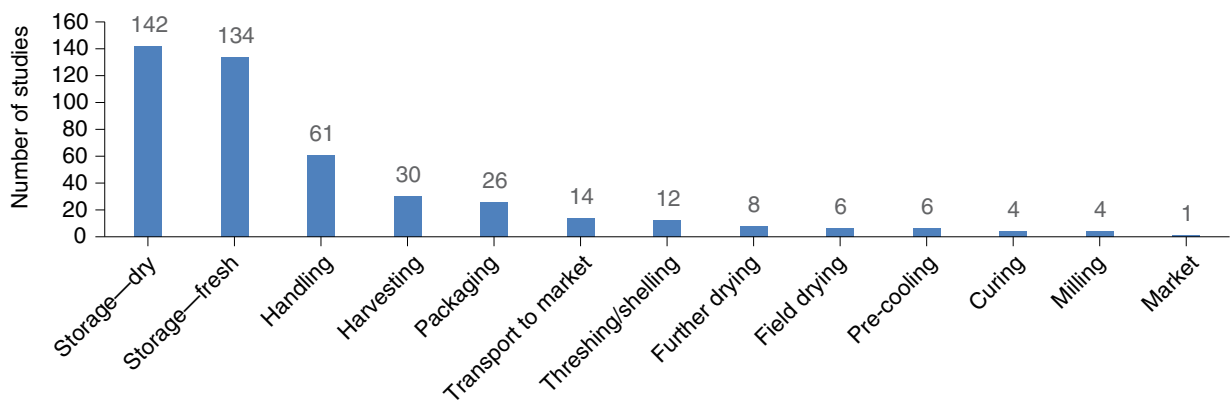

Fig. 1 | Profile of the 334 PHL reduction intervention studies. a-e, The number of studies by year (a), country (b), crop (c), crop group (d) and postharvest activity stage (e). 


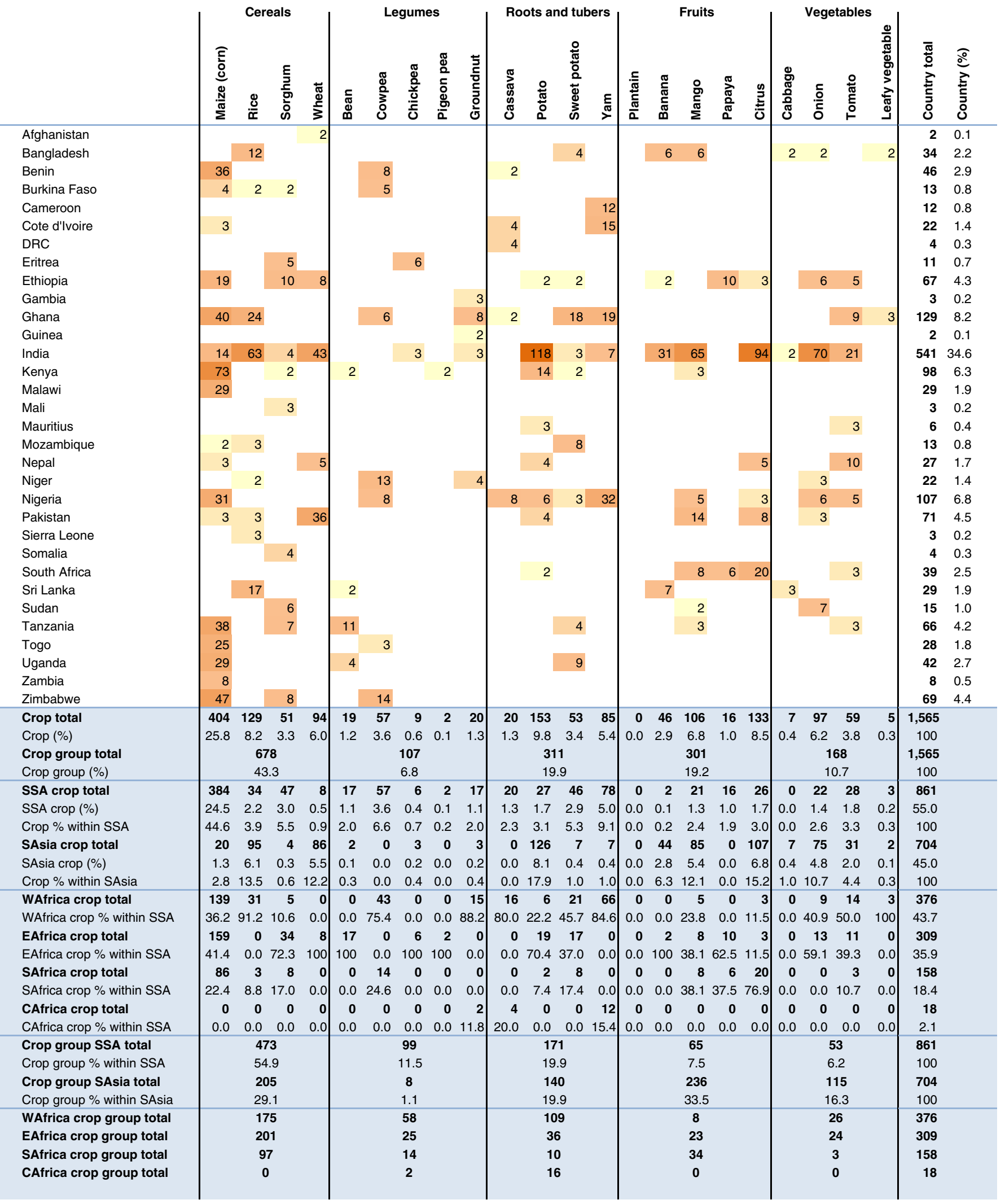

Fig. 2 | Number of PHL reduction interventions studied by crop, crop group, country and region. Derived from the dataset of 334 studies, the numbers in each cell specify the number of interventions studied for each specific crop and country combination. The darkest orange cells identify the crop-country combinations with the most data. The blank cells represent zeroes. The blue rows at the base of the figure show the total numbers and percentages of interventions studied by crop, crop group and region (SSA, South Asia (SAsia) and the geographical regions of SSA (WAfrica, West Africa; EAfrica, East Africa; SAfrica, Southern Africa; CAfrica, Central Africa)). 
Intervention type (tier 1) and

intervention stage (tier 2)

Technology/tool/equipment use

Ripening/senescence

Harvesting

Pre-cooling

Packaging (perishables)

Storage protectant (perishables)

Storage structure or container (perishables)

Drying

Threshing or shelling or de-husking

Storage method (durables)

Processing

Handling practice change

Handling before and/or after harvest

Harvest

Harvest and handling

Training/extension

Expert advice

Training

Infrastructure

Road transport

Crop total

Crop group total

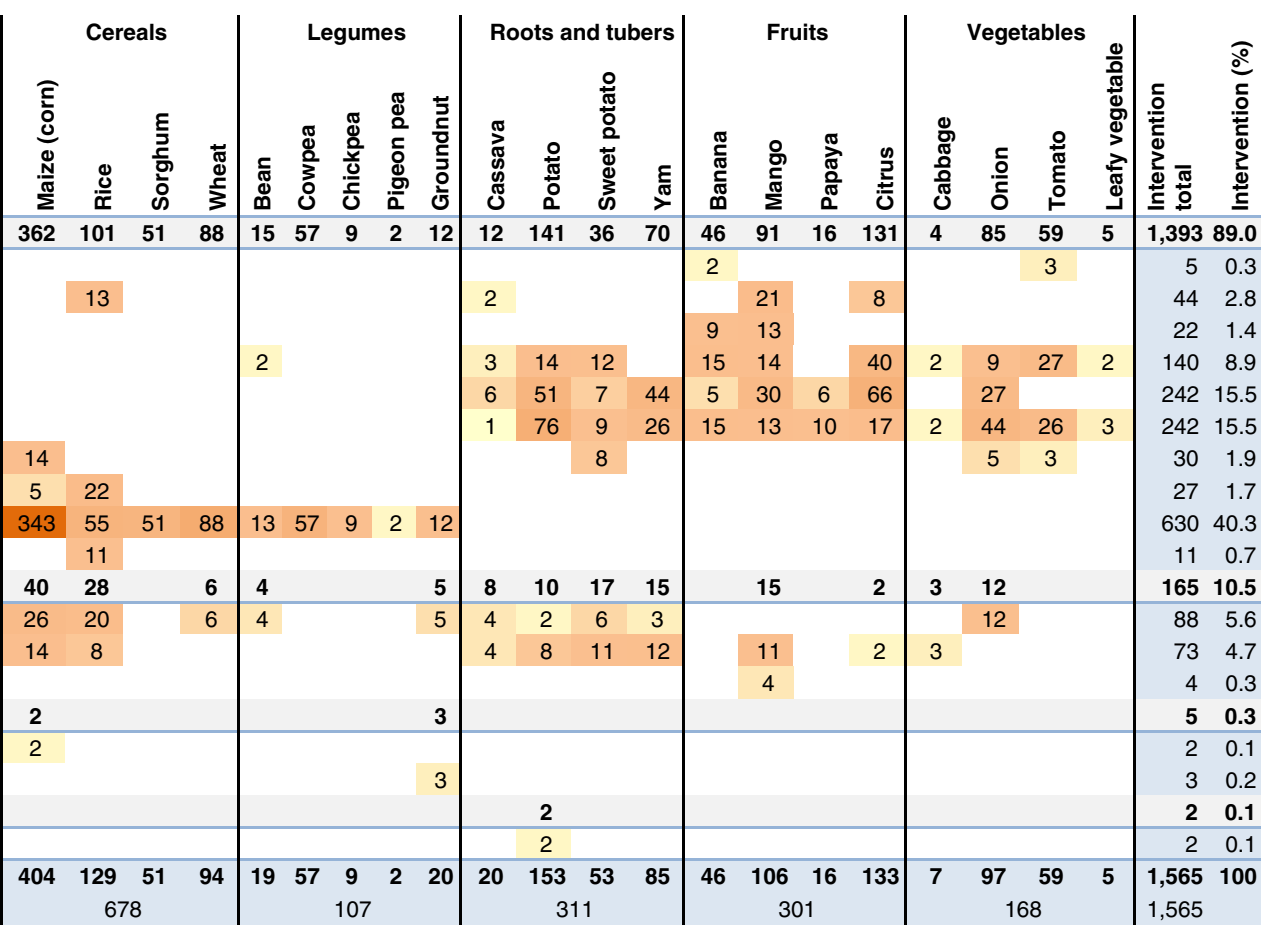

Fig. 3 | Overview of the number of PHL reduction interventions studied by type (tier 1) and stage (tier 2) and by crop and crop group. Derived from the dataset of 334 studies, the numbers in each cell specify the number of interventions studied for each specific crop and intervention stage combination. The darkest orange cells identify the crop-intervention stage combinations with the most data. The blank cells represent zeroes. The blue cells at the base of the figure show the total number of interventions studied by crop and crop group, and in the two rightmost columns by intervention type and stage.

a

b
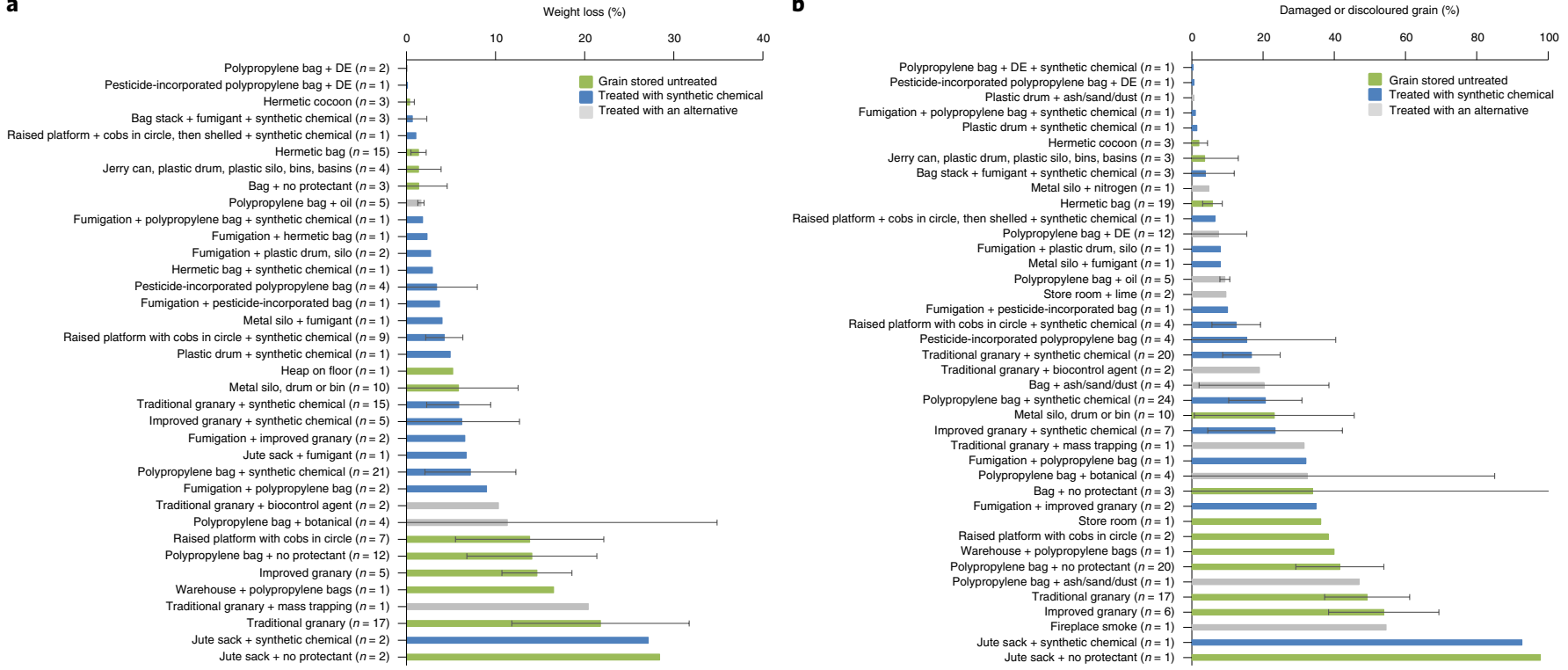

Fig. 4 | Comparative losses in quantity and quality of stored maize. a,b, Quantity (\% weight loss) (a) and quality (\% damaged or discoloured grain) (b) loss of maize stored for six months using different storage interventions. The interventions were sorted in order of efficacy. The means, $95 \%$ confidence intervals ( $\mathrm{Cls}$ ) and $n$ values (that is, the number of times this intervention was found in the 334 studies) are presented. The loss levels are dependent on numerous factors, including the conditions during the study, which can result in high heterogeneity between studies. The loss levels for each intervention need to be interpreted with caution, particularly where the $n$ value is low. Interventions in which the grain was stored untreated are shown as green bars.

The blue bars indicate grain treated with a synthetic chemical. The grey bars indicate grain treated with an alternative method, such as DE.

mechanical drying reduced rice weight loss, breakage and aflatoxin content compared with various field-drying and stacking combinations before threshing.
Legumes. There was considerably less research on legumes than on cereals. The majority of the studies $(86.9 \%)$ focused on storage methods of dried legumes (Fig. 3 and Supplementary Table 6). 
Cowpea accounted for more than half of the legume storage interventions studied (53.2\%). Storage loss was generally higher in legumes than in cereals, despite the shorter standardized storage duration of 4.5 months that was used. For example, when cowpeas or beans were stored in jute or polypropylene bags with no protectant, grain damage ranged from $46 \%$ to $70 \%$, and weight loss in cowpeas was $18.9 \%$ (Extended Data Fig. 4a,b).

The storage methods investigated included the effect of admixing pesticides (botanicals, synthetic chemicals, DEs or ashes) with grain legumes stored in bags (with and without air-tight liners), clay pots, plastic or metal containers, or traditional granaries.

Most of the legume loss data were for non-synthetic chemical interventions, such as cowpea storage in hermetic bags (Extended Data Fig. 4b). Hermetic bags were clearly more effective in reducing quantity and quality losses in cowpeas, groundnuts and beans, when compared with traditionally used practices or untreated controls (Supplementary Fig. 3a,b). Other interventions that kept the grain damage levels at least 20 percentage points lower than the untreated control included mixing synthetic chemicals, botanicals or DEs with cowpeas or beans before storing them in sacks (Supplementary Fig. 3b). The storage of cowpeas in clay pots, plastic jerry cans or drums reduced storage losses, but not as effectively as hermetic bags or synthetic chemicals. The protective effect of storing unshelled cowpeas was illustrated in one study ${ }^{19}$.

Only three legume studies compared handling practices (Supplementary Table 7). Simple handling practice changes, such as weekly sunning or sieving of beans, reduced storage damage to $3.6-4.1 \%$, compared with $37.7 \%$ in the untreated control ${ }^{20}$. Careful sorting and drying of groundnuts led to a striking reduction in aflatoxin $\mathrm{B} 1$ content (from $55 \mathrm{ppb}$ to $17 \mathrm{ppb}$ ), although still beyond the safe limits of most standards ${ }^{21}$. Harvesting groundnuts in the rain and slow drying, as opposed to rapid drying, increased fungal incidence on pods from $19.4-24.5 \%$ to $32.5-38.9 \%{ }^{22}$.

In a Gambian study, baseline samples of groundnuts had an average aflatoxin $\mathrm{B} 1$ content of $112.5 \mathrm{ppb}$ and a median level of $0.49 \mathrm{ppb}^{23}$. After 25 women were trained in sorting and removing any mouldy groundnuts, the resulting weight loss was $1.9 \%$, and the remaining groundnuts had an average aflatoxin B1 concentration of $0.28 \mathrm{ppb}$.

Roots and tubers. The majority $(70.7 \%)$ of the root and tuber crop interventions compared storage protectants (hot water dips, irradiation, growth regulators, biological control and pesticides) or structures (shade-providing structures, structures with forced air ventilation, evaporatively cooled and cold stores, and comparisons of traditional structures) (Fig. 3). Most of the interventions were on potato or yam; only $6.4 \%$ were on cassava.

In roots and tubers, quantity loss was measured as percentage overall loss, loss based on weight loss combined with decay and sprouting, and weight or water loss, except in one study. Quality loss measurements include percentages with decay, damage, infestation and unmarketable product (Supplementary Tables 4 and 5). Sprouting was analysed independently from decay because it tended to be inversely related. Storage durations ranged from 5 weeks to 44 weeks.

In potato, quantity and quality losses were less than $15.5 \%$ and $8.5 \%$, respectively, when the tubers were stored in improved pits, cold rooms, store rooms, evaporatively cooled or well-ventilated structures, or heaps without the use of chlorpropham (Fig. 5a). Storage with chlorpropham reduced losses regardless of the storage structure, whereas losses were higher under ambient conditions or in a traditional structure.

The use of botanicals, essential oils, biocontrol, heat or irradiation resulted in less than $20 \%$ quantity loss in yams, but not all of these treatments had similar effects on quality losses (Fig. 5a). When no protectants were used, quantity losses were high (29.0-44.0\%).
Irradiation reduced both quantity and quality losses, as well as sprouting. When curing was combined with a storage protectant, quality losses were low (10-14\%).

Biological control approaches included two studies evaluating Bacillus thuringiensis in potato storage in India and $\mathrm{Nepal}^{24,25}$, one assessing the performance of the predatory beetle Teretrius (Teretriosoma) nigrescens in protecting dried cassava chunks from attack by the larger grain borer during storage ${ }^{26}$ and one on storing yams in termitaria ${ }^{27}$

Sixteen percent of the interventions studied handling practice changes. These focused on the effect of harvesting from different soil types and moisture contents, piecemeal versus once-off harvesting, and timing of harvest, among others (Supplementary Table 7). Harvesting cassava from moist, less compacted soil resulted in lower damage $(21.6 \%)$ than from dry, compacted soils $(44.6 \%)^{28}$. Soaking cassava chips in water before sun-drying or smoke-drying reduced weight loss to $23.9 \%$ after six months of storage compared with $96.4 \%$ in unsoaked stored chips ${ }^{29}$. Piecemeal harvesting (11.3\%) resulted in lower losses in potato than once-off harvesting $(37.1 \%)^{30}$. Delayed harvesting led to increased insect damage on sweet potato ${ }^{31,32}$, while dehaulming lessened decay in roughly handled sweet potato roots ${ }^{33}$. Sorting and storage of undamaged yams led to no decay during 36 weeks of storage compared with $80-100 \%$ decay in yams with cuts ${ }^{34}$. In the only study on infrastructure, better road quality reduced losses of potato in Ethiopia ${ }^{35}$.

Fruits. In the fruit crops, quantity loss was measured as percentage overall loss, water loss or weight loss. Quality loss was typically expressed as percentage decayed, damaged or unmarketable. Other measurements reported in the studies were firmness, nutrient composition changes, assessment of visual quality and ripening stages. Unlike in cereal crop storage, where postharvest quantity loss can be directly correlated to some measures of quality loss, an inverse relationship can exist in fruits and vegetables. For example, if water loss (quantity) is high, then decay (quality) tends to be lower, and vice versa. This, along with the different storage durations and temperature conditions in each study, confounded comparisons.

For fruit crops, storage protectants accounted for $35.5 \%$ of the interventions, packaging $22.9 \%$, and storage structures/containers $18.3 \%$. Storage protectants focused on the use of waxes or coatings with or without fungicides, pesticides and heat treatments. Packaging interventions included fibreboard, wooden or plastic boxes with or without liners and padding, modified atmosphere packaging and shrink-wrapping. The storage structure interventions tested included evaporatively cooled structures, insulated rooms equipped with an air-conditioner controller with frost sensor override, and cold rooms. The less commonly evaluated interventions were harvesting tools, harvest maturity, pre-cooling and ripening. Handling practices accounted for $5.6 \%$ of the interventions and included combined sets of improvements compared with traditional handling practices.

Most types of packaging reduced quantity loss in citrus, but when liners were used, quality loss was higher. For example, packing in wooden boxes resulted in a $6.6 \%$ loss in quality, but when a liner was added, losses increased to $22.6 \%$ (Fig. 5b). This increase in decay was attributed to higher relative humidity. Shrink-wrapping reduced both quantity and quality loss. Storage protectant interventions for citrus were effective. With no protectant, fruits sustained high losses in quantity (34.3\%) and quality (33.7\%) (Fig. 5b). The use of waxes alone, with fungicides or with botanicals, reduced losses in both quantity and quality.

For mango, most storage protectant interventions reduced percentage quality loss (usually decay), but this was not always associated with a lower quantity loss (usually water loss) (Fig. 5b). Heat treatment (specifically hot water) $(13.0 \%)$ and pesticides $(16.6 \%)$ 
a

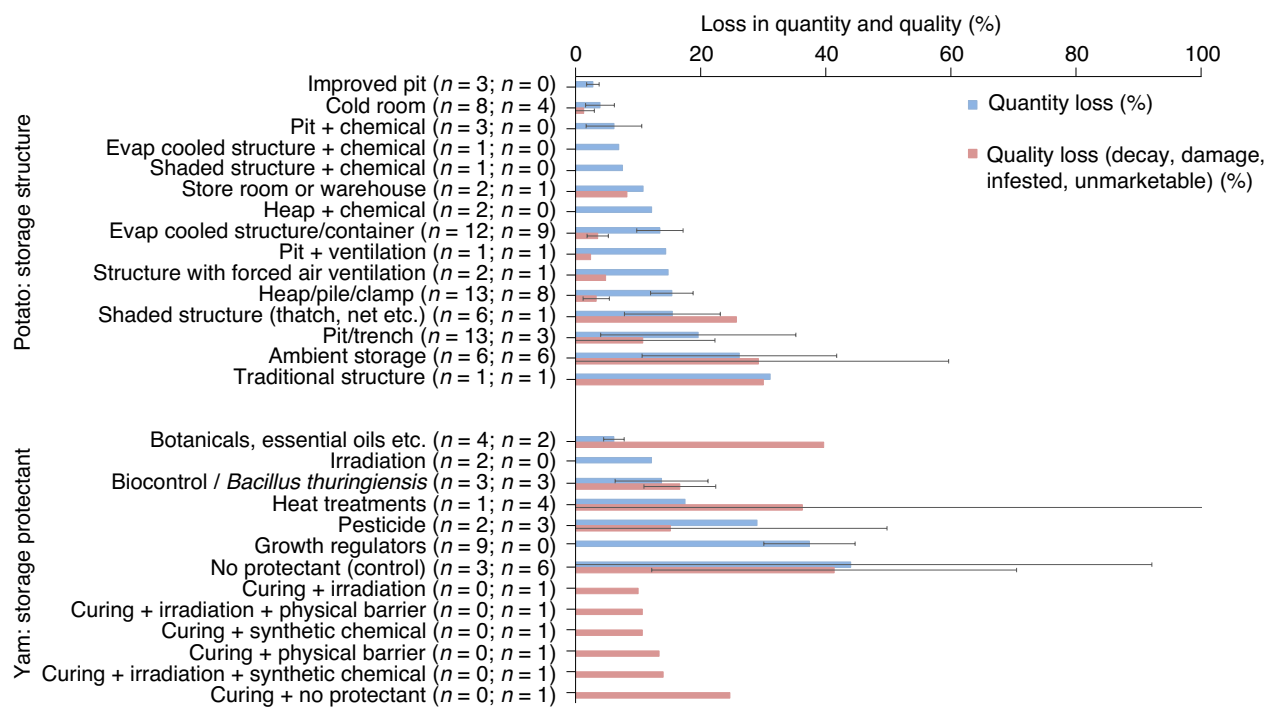

b

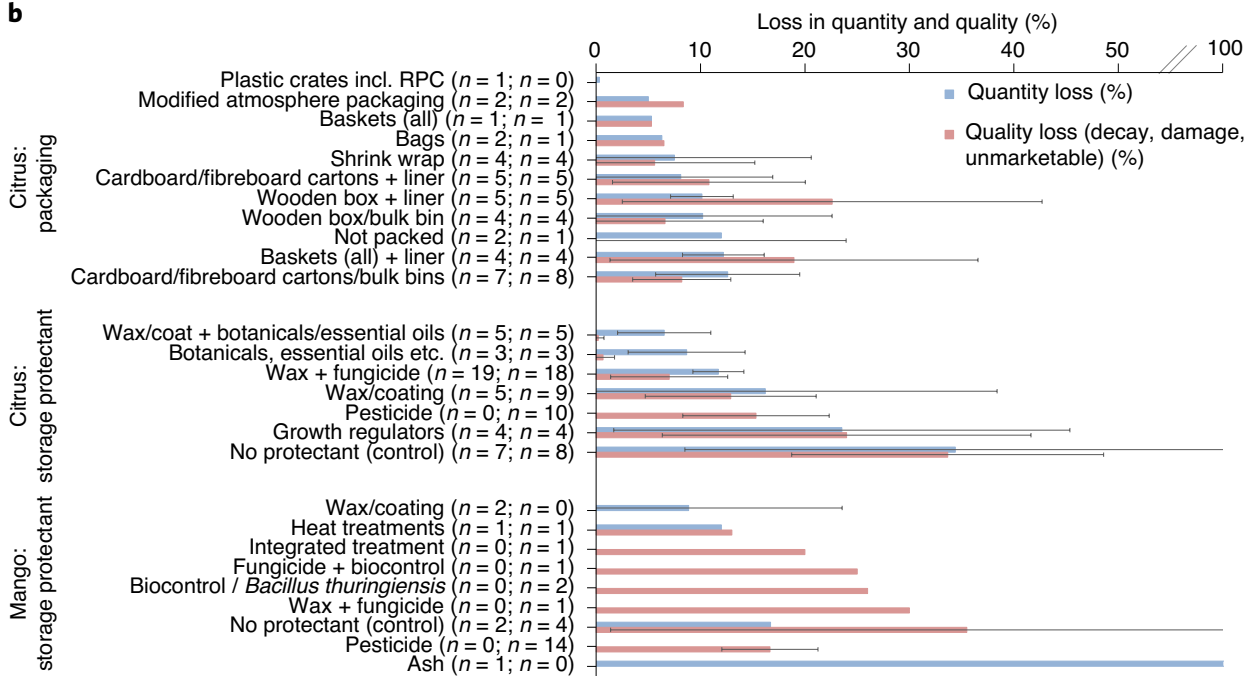

c

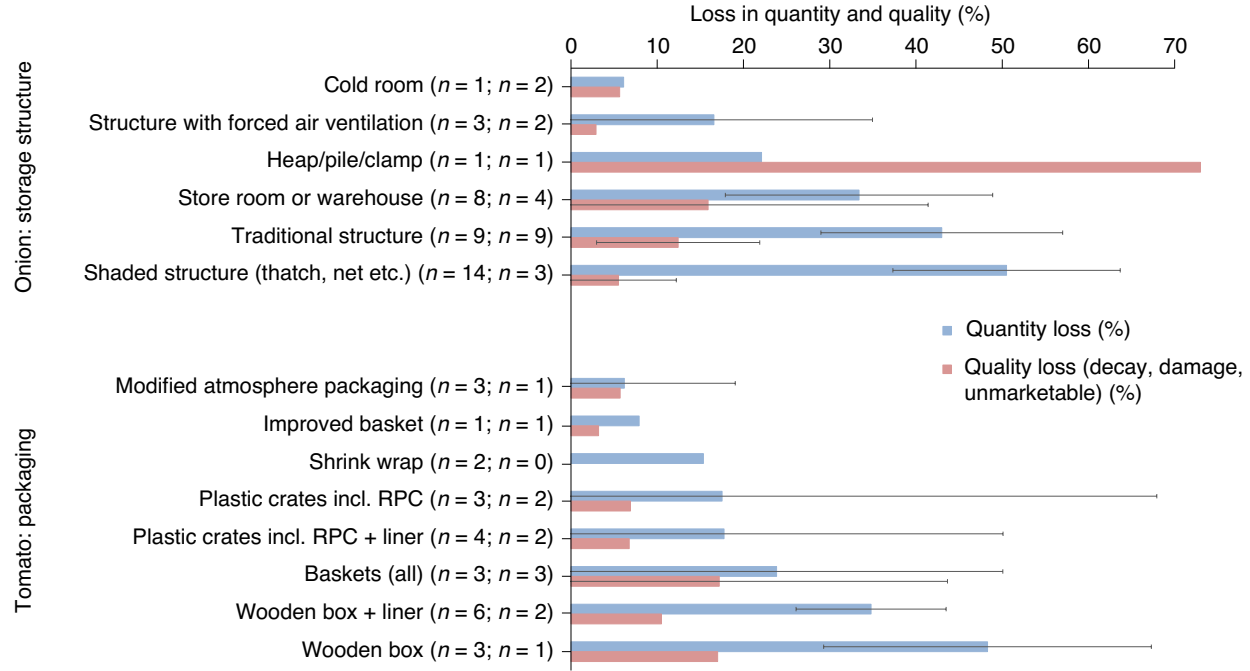

Fig. 5 | Quantity and quality losses associated with storage and packaging of roots and tubers, fruits and vegetables. a, Storage structures for potato and storage protectants in yam. b. Packaging for citrus and storage protectants in citrus and mango. c, Storage structures for onion and packaging for tomato. The mean percentage quantity loss (blue bars) and quality loss (red bars) and $95 \% \mathrm{Cls}$ for the different interventions are listed. For each crop and intervention combination, the first $n$ value indicates the number of examples of quantity loss data, while the second $n$ refers to the quality loss data. The loss levels are dependent on numerous factors, including the conditions during the study, which can result in high heterogeneity between studies. The loss levels for each intervention need to be interpreted with caution, particularly where the $n$ value is low. RPC, returnable plastic crates. 
were particularly effective in reducing quality loss over 9-14 days of storage, essentially by reducing decay. Mangoes stored without protectants experienced $35.5 \%$ quality loss.

Traditional handling of mango (conventional harvest, collecting in bamboo baskets and rough packaging in wooden crates) resulted in $25 \%$ quantity loss and $68.3 \%$ damage. Improved handling (careful harvesting with 10-15-cm-long pedicels, desapping in lime solution, washing in water and using the same containers) resulted in only $5 \%$ quantity loss and $22.5 \%$ damage $^{36}$ (Supplementary Table 7).

Vegetables. Onions were stored for durations ranging from 7 to 26 weeks, complicating comparisons between the storage structure interventions. The trends indicated higher quantity (22.1-50.5\%) and quality (5.5-73.0\%) losses in shaded or traditional structures, store rooms and heaps (Fig. $5 \mathrm{c}$ ). Lower quantity (6.1-16.6\%) and quality (2.9-5.7\%) losses occurred in structures with some control of air flow, relative humidity or temperature. Curing onions extended the shelf-life and reduced quantity losses from $47.0 \%$ to $31.0 \%$. Improved handling practices (curing, sorting, fungicide use and ventilation during storage) resulted in $32.3-40.3 \%$ quantity loss and $8.9 \%$ decay compared with $51.7 \%$ and $17.4 \%$, respectively, for poor handling practices (Supplementary Table 7).

Tomato studies focused on packaging and cool-storage technologies. Traditional packaging, such as wooden boxes or roughly made baskets, tended to cause higher losses in both quantity (23.8-48.3\%) and quality (17.0\%) (Fig. 5c). Plastic crates and improved baskets reduced quantity losses (7.9-17.5\%) and quality losses (3.2-6.9\%). Modified atmosphere packaging showed promise, with low quantity and quality losses (6.2\% and 5.7\%, respectively).

Social, economic and environmental outcomes. About $13.1 \%$ of the studies mentioned economic, social or environmental outcomes of the interventions, either separately or combined. Economic outcomes were reported by $12.5 \%$ of the studies, social outcomes by $3.0 \%$ and environmental outcomes by $1.2 \%$. Most of the reported economic outcomes were for maize, rice and potato. Nineteen studies reported on theoretical cost-benefit analyses. Nine studies directly mentioned the actual costs and benefits of interventions. Only $11.4 \%$ of the studies included information on the costs of the interventions. Costs ranged from less than US\$1 for harvesting tools, sacks, baskets, cartons, liners and protective padding to around US $\$ 2,000$ for cold rooms cooled evaporatively (20t capacity) or with a modified air-conditioner (8-10t capacity). The cost was US $\$ 4,000$ for a 20 -t-capacity hermetically sealed cocoon and US\$36,000 for a combine harvester (Supplementary Table 8).

Some grain storage intervention studies highlighted the links with lower aflatoxin risk and reduced food consumption volatility $^{37}$. Other studies emphasized that while mechanized harvesters, reapers or threshers reduce drudgery, they can also displace labour ${ }^{38-40}$. None of the studies reported on gendered outcomes. Just two studies ${ }^{41,42}$ reported on the economic, social and environmental outcomes simultaneously. These studies showed that the use of improved containers for maize storage reduced chemical use and increased the ability to smooth out consumption and net revenue, as well as increasing the cultivation of high-yielding but storage-pest-susceptible hybrid varieties.

Barriers to and facilitators of adoption. Just five of the articles studied the factors affecting the adoption of PHL reduction interventions. Four were on maize storage, drying or handling in East African countries ${ }^{37,41,43,44}$, and one was on rice threshers in Sri Lanka ${ }^{45}$. The efficacy, lifespan, durability and cost-to-economic-benefit ratio of the technology were positively related to the adoption rate of the interventions. Household size, literacy, land size, use of financial services and off-farm income also had positive relationships with the adoption rate. In contrast, the distance from passable roads and the presence of a female primary decision maker reduced the likelihood of using a metal silo.

Many of the other studies made suggestions regarding barriers and facilitators of the adoption of PHL reduction interventions without supporting data. Suggested barriers to adoption included high initial investment costs, limited availability of distribution channels, lack of participatory development and testing by farmers and value-chain actors, and limited awareness of the scale of the problem. There were also complex trade-offs, such as bulkier packaging or grain protectant methods that reduced seed viability. Lack of credit, subsidies or input markets were also viewed as barriers.

Suggested factors facilitating adoption included cost-effective, time-saving, technically effective and easily maintained interventions; the availability and ease of integration of the interventions with existing practices; quality-sensitive markets; the use of participatory multistakeholder learning-by-doing approaches (such as learning alliances and living labs); and postharvest training and awareness-raising among farmers and value-chain actors.

\section{Discussion}

This study investigated PHL reduction interventions for 22 crops across 57 countries of SSA and South Asia from the 1970s to 2019. The identification of just 334 studies highlights the limitations of this evidence-base, particularly as one country, India, accounted for $108(32 \%)$ of these studies. Interventions for cereals (particularly maize) dominated, whereas vegetables and legumes have received much less attention. The increasing trend in the overall number of studies during the past two decades suggests growing recognition of the need for PHL reduction. However, the lack of studies on training, finance, infrastructure, policy and market interventions highlights the need for interventions beyond technology or handling practice changes.

Most of the studies focused on the effect of a technology, tool or piece of equipment during farm-level storage. While interventions to reduce storage losses are crucial, a better understanding of losses during non-storage stages and interventions that can reduce these losses is also needed. PHLs are the cumulative result of a sequence of actions (or inactions) and conditions along the value chain. Given the rapid transformation of food systems in SSA and South Asia-linked to population growth, urbanization, changing dietary choices and climate variability, among other drivers-there is an urgent need for evidence on interventions that support other value-chain actors beyond farmers in reducing PHLs, and not only during the storage stage. For perishable crops, for example, this would require studies that include maturity assessment, harvest method, handling, cooling, packing/packaging, transportation, storage and drying or processing.

Most storage studies included a traditional practice or untreated control as a comparator. In reality, traditional practices may be more dynamic than researchers recognize ${ }^{46}$. As emphasized by Ng'ang'a et al. ${ }^{47}$, "farmers, unlike scientists do not wait for 35 weeks to see their storage losses go up to $79.6 \%$ ". Additionally, there is limited evidence on common-sense good practices, such as cleaning or disinfesting a store before use and careful handling of perishable crops.

A sound evaluation of postharvest interventions requires a more complete assessment of their efficacy in reducing losses in both quantity and quality. Future research (and evidence syntheses drawing on it) would benefit from employing more systematic and uniform collection methods of a wider array of data.

It is also worth noting that some postharvest interventions, such as mechanization, save farmers time and drudgery but may increase quality and quantity losses. This highlights just one aspect of the complex trade-offs surrounding PHL reduction. 
Table 1 | Summary of the PHL reduction interventions evidence-base for SSA and South Asia

\begin{tabular}{|c|c|c|c|}
\hline & \multicolumn{2}{|c|}{ Technically effective interventions } & \multirow[t]{2}{*}{ Critical gaps in the evidence-base } \\
\hline & Technologies, tools and equipment & Handling practices & \\
\hline Cereals & $\begin{array}{l}\text { Maize storage: in hermetic containers or } \\
\text { admixed with some synthetic chemicals or DEs } \\
\text { Wheat, rice or sorghum storage: in hermetic } \\
\text { containers or underground pits, or admixed with } \\
\text { some synthetic chemicals, botanicals or DEs }\end{array}$ & $\begin{array}{l}\text { Timely harvesting, protecting } \\
\text { crops from direct ground contact } \\
\text { while drying }\end{array}$ & \multirow{5}{*}{$\begin{array}{l}\text { - Interventions for loss reduction in the } \\
\text { non-storage activity stages } \\
\text { - Any evaluation of training, policy, infrastructure, } \\
\text { finance interventions on loss reduction } \\
\text { - Effects of sanitation, grain cleaning and timing } \\
\text { of activities on subsequent losses } \\
\text { - Verified measured socio-economic or } \\
\text { environmental outcomes of the uptake } \\
\text { of different PHL reduction interventions } \\
\text { at any scale } \\
\text { - Factors facilitating and constraining the } \\
\text { adoption of PHL reduction interventions } \\
\text { - Stakeholder participation in the study of } \\
\text { interventions to facilitate co-innovation and } \\
\text { co-learning, and the need for more real-world } \\
\text { scale on-farm participatory studies } \\
\text { - Standardized loss measurement metrics } \\
\text { - Consistency of intervention results confirmed } \\
\text { through multiseason and multilocation studies }\end{array}$} \\
\hline Legumes & $\begin{array}{l}\text { Storage in hermetic containers or admixed } \\
\text { with synthetic chemicals, botanicals, DEs } \\
\text { or edible oil }\end{array}$ & $\begin{array}{l}\text { Protecting crops from direct } \\
\text { ground contact while drying, } \\
\text { sorting to remove mouldy grains }\end{array}$ & \\
\hline Roots and tubers & $\begin{array}{l}\text { Use of digging tools that reduce harvesting } \\
\text { damage, use of improved storage containers, } \\
\text { ventilated storage, evaporative cool storage, } \\
\text { cold storage, sprout suppressants }\end{array}$ & $\begin{array}{l}\text { Piecemeal harvesting, curing, } \\
\text { sorting to remove damaged roots } \\
\text { or tubers, avoidance of rough } \\
\text { handling, use of maturity indices }\end{array}$ & \\
\hline Fruits & $\begin{array}{l}\text { Harvesting poles/pickers, use of improved } \\
\text { packaging, waxing (alone or with fungicides or } \\
\text { botanicals), hot-water treatments, evaporative } \\
\text { cool storage, cold storage, ripening treatments }\end{array}$ & $\begin{array}{l}\text { Use of maturity indices, gentle } \\
\text { harvesting and handling, sorting } \\
\text { to remove damaged fruits }\end{array}$ & \\
\hline Vegetables & $\begin{array}{l}\text { Use of improved packaging, evaporative cool } \\
\text { storage, ventilated storage (onions), cold storage }\end{array}$ & Gentle handling, curing (onions) & \\
\hline
\end{tabular}

The interventions for which sufficient evidence existed of their efficacy in reducing PHLs are listed for each crop group. These interventions were either of the technologies/tools/equipment type or of the handling practices type, and they predominantly focused on reducing losses during the crop storage stage. Critical gaps identified in the evidence base for all crop groups are listed in the final column.

Drawing robust conclusions on the technical efficacy of many of the interventions is difficult because there are relatively few studies of each intervention for each crop, and they vary in scale, duration, type of loss data collected, location and context. Many studies were excluded because they used very small quantities of the crops, were conducted only in the laboratory or did not replicate the interventions. Most of the included studies involved only researchers without any participation from farmers or other community members. Their participation could have provided experiential learning opportunities and built ownership. Even if technically effective in researcher-managed trials, such interventions may not be as effective in real life and may not be acceptable to or affordable for farmers. Additionally, more data on multiseason and multisite testing of interventions are required to provide a critical understanding of their replicability and degree of variation. Loosening the inclusion criteria would increase the number of studies, but it would compromise the value and quality of evidence on which the synthesis was based.

Despite the systematic approach used and the recognition of the four principles (inclusive, rigorous, transparent and accessible) identified by Donnelly et al. ${ }^{48}$ for synthesizing evidence for policymakers, the present evidence-base is subject to non-publication bias, as studies of less effective interventions would not have been widely shared. Furthermore, where there is no requirement for $\mathrm{PhD}$ or MSc theses or project reports to be registered in public databases, digital search strategies do not always identify these important sources of evidence. Several studies did not acknowledge all the treatment details. For example, the additional cost and effect of prior fumigation on grain storage interventions was rarely recognized. Details of the concentrations and application rates of active ingredients of protectants were not always available, even though they are important for efficacy comparisons, as well as compliance with national product registration and safety regulations. Some grain storage trial durations were very short. The efficacy of the tested interventions may be different during the longer storage durations (six to ten months) required by many small-scale producers to ensure the availability of their staple grains between harvests and in response to increasingly unpredictable climate ${ }^{11,41,49-54}$. Such issues highlight opportunities to support systems to improve PHL reduction research methods, data analyses and interpretation. Recent initiatives and funders' forums set up to ensure value in medical research may offer prospects for cross-learning ${ }^{55}$.

Well-designed, multidisciplinary, measured field studies should analyse the links between reductions in different types of loss and their social, economic and environmental outcomes. This will support better understanding for the development, adoption and promotion of PHL reduction interventions in their various forms, such as technologies, policies, training, infrastructure and combinations of these. There is also a need to understand the factors that facilitate or constrain the adoption of interventions. A small body of literature exists on this, although much of it is focused on the adoption of relatively expensive interventions ${ }^{43,56-60}$. Cost, access, ease of use and reuse, cultural acceptability, one-time subsidies, willingness to pay, scale, awareness and demonstrations, and training are just some of the factors influencing the uptake of PHL reduction interventions along with technical efficacy ${ }^{11,46,61-73}$.

Notwithstanding the limited size of the evidence-base, the efficacy of a number of interventions in reducing PHLs was recognized. A summary of these notable interventions and critical gaps in the evidence-base is presented in Table 1 , followed by a set of policy recommendations (Box 2). A deeper analysis of the dataset is available from the authors, and the interactive database at https:// PHCeres2030.net/, which will be updated biannually, provides users with an opportunity to identify relevant studies and better tailor the data outputs to their specific needs.

This evidence-based analysis demonstrates that future PHL reduction research and investments need to be expanded to include a more diverse range of food crops, food systems actors and postharvest activity stages. Future research and investments should also cover combinations of training, finance, infrastructure, policy and market interventions that go beyond tangible technologies and handling practice changes. Besides a more participatory study of the technical efficacy of interventions, there is also a need to explore social, economic and environmental outcomes, and barriers and facilitating factors to adoption to inform policy 


\section{Box 2 | Policy and investment recommendations}

- Studies should be conducted to increase the available data on PHL reduction interventions, particularly for legumes, small grains, root and tuber crops, fruits, and vegetables. Notably effective PHL reduction interventions, along with critical gaps in the evidence-base, are presented in Table 1.

- Future studies should include the non-storage activities in the value chain and the key actors (such as farmers, traders, transporters and wholesalers), because to date the focus has been predominantly on tangible technical interventions to reduce losses during farmer-level storage.

- The limited evidence on PHL reduction interventions can be extrapolated to similar crops within each crop group, with participatory field-level studies to confirm and expand the evidence.

- The effects of training, finance, policy and infrastructure interventions on PHL reduction need to be studied to guide investments.

- More evidence is needed regarding verified socioeconomic and environmental outcomes of PHL reduction interventions, because to date the focus has been on their technical efficacy.

- More evidence is needed on the efficacy of PHL reduction interventions, particularly when technologies are combined with interventions such as training, changes in handling practices, access to finance and policies.

- Future studies would benefit from collecting a wider array of data using uniform and more systematic methods to capture the quantitative, qualitative and socio-economic aspects of PHLs.
- For improved postharvest management and loss reduction, there is a need for:

1. Greater efforts to raise the awareness of stakeholders of the ability to reduce losses and the benefits of doing so 2. Recognition that all technologies have strengths and weaknesses and that due to the heterogeneity between households, agro-ecologies and crops, one-size-fits-all solutions are unlikely to be successful

3. Technical solutions to be simultaneously promoted alongside good postharvest training and management to build understanding of why losses are occurring, how the technologies can best be used and the local costs and expected benefits of interventions

4. More study of how national policies, financial access and infrastructure investments affect PHL reduction 5. Implementation of policies that support quality-sensitive markets to provide incentives for PHL reduction 6. Multistakeholder postharvest platforms or institutions to promote co-learning and co-innovation, support access to information, and support multilocation and multiseason studies with active participation of stakeholders along the commodity value chains

- Targeting of the aforementioned recommendations may be needed depending on limitations of financial resources and information, and whether the main objective for reducing PHLs is improved food security and nutrition or lower environmental impacts. and guide investments that can drive PHL reduction in food systems at scale.

\section{Methods}

Research question. The research was guided by the main question: what are the interventions that small-scale producers and associated value-chain actors in SSA and South Asian countries can adopt or adapt to reduce PHLs along food crop value chains? A secondary research question was: what are the associated barriers and facilitating factors for adoption of the interventions?

This analysis focused on SSA and South Asia, both regions with large populations of small-scale producers dependent on local food systems and where PHLs and the incidence of poverty are relatively high. Interventions applicable to small-scale food producers and/or their associated value-chain actors such as aggregators, packers, operators of driers, threshers, chippers, transporters, processors, traders, and other service providers (for example, training, extension, financial and market information services) were targeted to meet the food demands in these regions. Narrowing the focus to 22 key food crops from five crop groups (cereals-maize, rice, sorghum and wheat; legumes-beans, cowpeas, pigeon peas, chickpeas and groundnuts; roots and tubers-cassava, potato, sweet potato and yam; fruits-plantain, banana, mango, papaya and all citrus fruits including orange, lemon, lime and mandarin; and vegetablescabbage, onion, tomato and leafy vegetable) allowed for deeper analysis. There were no prior specifications of the types of interventions, as any interventions that apply to PHL reduction in food crop value chains are relevant, including training, information, handling practices, skills, institutional changes, financial interventions, policies, postharvest infrastructure, tangible technologies and any combinations of these.

To measure the effectiveness of the interventions, comparisons included those between different interventions, between adopters and non-adopters, and between pre- and post-adoption of an intervention. The comparisons could be vis-à-vis their technical, economic, environmental or social efficacy and outcomes. Intervention efficacy was evaluated by the level of PHL that occurred as well as the reduction in PHL compared with the traditional practice or untreated control in each study.

To ensure consistency during screening, key terms such as 'postharvest', 'loss', 'adopt', 'intervention', 'field-tested postharvest interventions', 'small-scale food producers' associated value-chain actors' and 'food crop value chain' were defined. The definitions are given in Supplementary Table 9.

Search strategy. A comprehensive search strategy was developed to identify the relevant published and grey literature. The search terms included variations of the key concepts in the research question: PHLs in quantity or quality, postharvest activity stages, PHL causing factors, focal food crops and focal countries. The search strings used are shown in Supplementary Table 10a-c. The following online databases of peer-reviewed publications were sequentially searched on 27 May 2019: CAB Abstracts (date coverage, 1973-2019), Web of Science Core Collection (date coverage, 1900-2019) and Scopus. These searches returned 8,880 records, 3,570 records, and 315 records, respectively, after screening for duplicates using Zotero bibliographic software. The searches were not limited by date or language. However, the search terms were done only in English. The search strategy was pretested and refined, and it used eight benchmark articles to maximize its comprehensiveness (Supplementary Table 11). However, three of the eight benchmark articles (a 1991 Acta Horticulturae study and two grey literature reports) were not indexed and were not accessible in any of the databases searched. In addition, 47 electronic database and grey literature sources identified by the postharvest team members were searched by librarians on 24 May 2019 (Supplementary Table 12). These grey literature searches involved various combinations of the following terms: 'post-harvest', 'post-harvest loss', 'post harvest losses,' 'post harvest', 'postharvest', 'value chain', 'crops' and 'food'. After searching, the results were screened to ensure that 'postharvest' and 'loss' were found in each report. These searches returned 1,811 records, which were combined with those from the databases to give 14,576 records, which were deduplicated using a Python (v.3.8.0) script. Duplicates were detected using the title, abstract and year of publication, where the year of publication was a match, the title cosine similarity was greater than $85 \%$ and the abstract cosine similarity was greater than $80 \%$ (or one or both of the abstracts was missing). When this occurred, the duplicate entry was removed. $\mathrm{CAB}$ Abstracts was the priority source of record. In contrast to the PHL review in six SSA countries by Affognon et al. ${ }^{11}$, where grey literature physically acquired through national teams made up $57.3 \%$ of the documents, the current study's digital search strategy captured relatively few $\mathrm{PhD} / \mathrm{MSc}$ theses, working papers or project reports.

The bibliographic details for each of the resulting 12,786 peer-reviewed and grey literature documents were exported into MS Excel (v.2002) for machine 
processing before title and abstract screening by the team. A second search phase of the three online literature databases for the year 2019 was done on 30 October 2019 to ensure that the evidence-base was as current as possible. The search returned 84, 52 and 15 records from CAB Abstracts, Web of Science and Scopus, respectively. After deduplication, 121 additional studies remained for screening.

Study inclusion and exclusion criteria. The following exclusion criteria were applied to the title and abstract and the full-text review stages.

- Irrelevant crop: study does not include a PHL reduction intervention for one of the 22 focal food crops.

- Irrelevant geographical area: study does not take place in the target geographical area of SSA and South Asia.

- Irrelevant target actor: study is not relevant to PHL reduction by small-scale producers or their associated value-chain actors.

- Irrelevant study type: study is a review or does not contain any original research or sufficient details on the original research to make an evidence-based decision about the intervention's efficacy.

- Irrelevant data output: study does not report the effect of an intervention on PHL.

- Irrelevant scale of study: study reports the effect of an intervention that was not tested at the field level or in a real-world context. In other words, the intervention was tested only at a small scale in a laboratory or tested in the field or on-station but with a treatment replicate size too small to provide reliable data on which to base investment decision-making.

In the studies of the durable crops, interventions on maize using less than $50 \mathrm{~kg}$ per treatment replicate were excluded, while for sorghum, rice and wheat studies, those with less than $25 \mathrm{~kg}$ per treatment replicate were excluded. For the five legume crops, studies with less than $10 \mathrm{~kg}$ per treatment replicate were excluded. Additionally, interventions were excluded where stored crops were artificially infested with insects, fungi or bacteria, or where crops were frozen before study to disinfest them. If the study had crops that had been fumigated before the intervention, the study was included. The fumigation aspect was then added to the intervention's description.

In the studies of the perishable crops, those with less than $20 \mathrm{~kg}$ per treatment for roots and tubers and with less than $10 \mathrm{~kg}$ per treatment for fruits and vegetables were excluded. For studies where the number of fruits was stated but the weight was not, we used a typical weight for that produce type to determine inclusion or exclusion. Studies that failed to state the size used in the treatments and where the size could not be inferred from the data were excluded. For some studies, in which the interventions were evaluated on a range of different grades or varieties, the results were averaged to achieve the weight expectations required for inclusion.

- Language: studies written in a language other than English or French were excluded.

- Date: no date restrictions were applied, but the searches were limited due to the coverage of the individual databases searched.

Title and abstract screening. The titles and abstracts of the search outputs were auto-coded by semantic machine-learning models and then prescreened by six team members in MS Excel using filters and a Python script to expedite the identification and exclusion of studies not related to the focal crops or geographies. The auto-coded fields-topics, countries, plant and animal products, populations, outcomes, interventions (technology, socio-economic, ecosystem, storage and mechanization) and measurements for interventions and for crops-were intended to help derive metadata from the individual citations for later sensitivity analyses and expedite the process of synthesizing the evidence. However, these fields were not found to be sufficiently accurate for this study. For example, the machine could not distinguish between countries mentioned in the title, abstract, bibliographic information or organism names (for example, Rhyzopertha dominica) and the country where the study happened, as it could not understand the context. Further training of the machine in close collaboration with expert researchers would improve the utility of the auto-coded outputs, but the rapid start-up and tight time frame of this study meant that building a more contextual base to train the machine was out of our scope.

The auto-coded search outputs were then imported into the web-based software platform Covidence for screening. Those studies identified for exclusion during the prescreening filtering (that is, wrong crop or wrong country) were then manually excluded on Covidence. For each of the 12,786 studies, the title and abstract were screened independently by two of the postharvest researchers. The eligibility criteria were used to decide which of the studies to include. Where there was uncertainty, the study was assigned to the 'maybe' category. If the reviewers' independent scoring disagreed or if the study was placed in the 'maybe' category, a third reviewer screened the title and abstract and made the final decision. To align the scoring, the first 20 disputed studies were discussed by the screening team to develop consistency. In cases where there was insufficient information in the title or abstract to exclude the study, the study was included so that the decision could be made at the full-text-screening stage. Filters in Covidence were used to search for studies on the specific focal crops, and two or three members of the team of five postharvest researchers screened the studies for each crop group. There were many irrelevant studies in the initial library (for example, studies on cocoa or coffee beans, silage or soil; reviews; and studies from other countries and languages), and filters were used to search for and exclude them. The titles and abstracts of the additional 121 studies from 2019 were double-screened using MS Excel, and the reasons for exclusion were recorded. The use of Covidence for the title and abstract screening enabled the records to be double-blind screened and the decision on whether to include them to be captured. However, it did not enable the reasons for exclusion to be recorded.

Full-text article screening. A total of 1,887 studies from the initial search and 19 from the 2019 updated search were selected for full-text article screening. The full texts were sourced by the librarian team members from July to December 2019. They were grouped into six batches on the basis of the timing of their acquisition. The full-text PDFs for each batch were placed in the team's Google Drive folder, and the MS Excel list of titles and abstracts in each batch was further machine-processed to assist in identifying the perishable and durable crop studies to help divide the articles between the screening members of the team. After reading each assigned article, the screening team members recorded their decisions in their MS Excel sheet. For the excluded studies, the reason for exclusion was recorded. This information was later entered into Covidence to produce the summary data on inclusion rates and exclusion reasons (Extended Data Fig. 1). If there was uncertainty regarding the inclusion of a study, it was checked and discussed with at least one other member of the team. Fleiss' kappa score was used to measure the level of agreement between screeners and gave a score of 0.659 for the three main screeners, who screened $83 \%$ of the 1,788 available full-text articles, indicating that the level of agreement was substantial $(0.61-0.80)^{74}$.

The coding framework was developed and trialled by the researchers using four of the benchmark studies, followed by discussions and amendments before finalizing and registering the protocol on the Open Science Framework at https:// osf.io/6zc92/ (Supplementary Table 2). An interactive SQL database and web app were built on the basis of the coding framework for entry of the relevant data extracted from each of the studies. This database is available for policymakers to explore the results.

Due to uncertainty regarding how many of the 12,786 records from the initial search would be included, a two-part full-text coding approach was initially planned. However, due to the time it took to obtain PDF copies of the 1,887 full texts and the short time frame available for the evidence synthesis, it was not feasible to wait for Part I screening of all the included full-text articles to be done to randomly select a sample of the included studies from across the different postharvest stages, crops and geographies. The Part II data extraction would have been conducted from this sample. After the full texts of batches 1 and 2 were screened, the inclusion rate was around $20 \%$, so the team decided to do the Part I and II data extraction on all the included full-text studies after the screening of each batch.

The relevant data were extracted into the database using drop-down menus based on the coding framework categories. The database structure was finalized in October 2019. In hindsight, the database should have included more options for the quality loss data, as more than one set of measurements was often available (for example, percentage damage, percentage decay, percentage sprouting, percentage germination and aflatoxin content). Each included study was coded by one reviewer for Part I and II data extraction, and any uncertainties were discussed. Three of the researchers extracted the data for $88 \%$ of the studies. For the 40 studies where data were extracted by other team members, one of the three main data-extracting researchers then went through them in the database to check and standardize data capture across the 334 included studies.

In addition to its bibliographic information, the researchers extracted data for each article using a two-part coding framework (Supplementary Table 2). Part I data comprised the following: geographic locations (country, region and village), focal crops, crop form (fresh, dried, shelled or on the cob), focal postharvest activities (harvesting, handling, field drying, transport to homestead, curing, cooling, further drying, threshing/shelling, milling, packing, storing dry, storing fresh, transport to market and wholesale market), targeted postharvest actors (small-scale producers/point of production; packers and processors; service providers of harvesting, drying, milling, storage and transport; and traders, middlemen or collectors), type of study (field or on-farm trial, on-station trial or survey), study method (quantitative, qualitative, survey or mixed), study design (comparison with traditional practices, other types of intervention, non-adopters or pre- and post-adoption) and funding source. The classification of the interventions was based on a four-tier hierarchical system, with the first tier being the intervention type (technology/tool/equipment, handling practice change, training/extension, finance, policy, markets, support or infrastructure). These were further divided into a second tier, intervention stage, where the interventions were grouped into typical postharvest stages (for example, harvesting, drying and storage). Tier 3 consisted of specific interventions (for example, zero-energy cool chamber and traditional granary plus synthetic chemical) (Supplementary Table 3 ). Detailed descriptions of the intervention were then provided in tier 4 (for example, name and application rate of the agricultural chemical, size of the box or specific details of the traditional granary). Tier 4 was included for reference but not used in the data synthesis. In Part II, the following were captured: the PHL measurements 
of quantity or quality; facilitators and barriers for adoption; study design, duration and scale; intervention cost; and any assessment of any social, economic or environmental outcomes associated with the interventions.

Thanks to programming expertise within the team, machine-scraped sections of the PDF files were placed in special fields in the database to support faster data extraction. However, the research team found that for accuracy and comprehension, validation still required reading of the paper and manual extraction of the required content. Moreover, the challenge in this body of literature has been that authors often use terms interchangeably, making codifying context difficult. In addition, given that this exercise in assessment is still new, building the knowledge base to train algorithms to function more accurately is a process that takes years. Given the complex and nuanced understanding required, we do not yet have machines that can sufficiently and accurately identify or automatically extract the relevant information from complicated postharvest research studies. But if leveraged correctly, this dataset can be used to build a more effective algorithm.

Data synthesis. The captured data were downloaded into MS Excel and synthesized using pivot tables. The meta-analysis was conducted at both the study level and the intervention level. A few studies covered multiple crops, multiple countries or multiple postharvest activity stages. Each study reported on at least 2 and as many as 24 interventions. For the meta-analysis, the means of the quantity and quality loss figures for the interventions (tier 3 ) were pooled. If $n>2$, the confidence limits (95\%) were calculated for these pooled means, and the data were presented within the relevant tier 1 and 2 categories. For storage method interventions for durable crops (that is, dried cereals and legumes), the quantity and quality loss data were adjusted to a standardized storage time of 6 months for cereals and 4.5 months for legumes to facilitate comparisons and represent typical storage durations for these crops in these geographical regions. The data on storage methods for perishable crops were presented without adjusting for storage time. Temperature is the most important factor affecting the storage life of perishable crops, and its effects are not linear. The wide range in treatment temperatures used in the studies (from $<5^{\circ} \mathrm{C}$ to $>38^{\circ} \mathrm{C}$ ) made standardization by storage time for perishable crops inappropriate, even for ambient conditions. Multiple comparisons of the mean quantity and quality loss data for storage interventions of the durable crops were conducted. The Least Significant Difference test function in the $\mathrm{R}$ agricolae package $\mathrm{e}^{75,76}$ was applied to the output of a one-way analysis of variance using a Holm-corrected least significant difference method to generate groups of means that do not differ significantly at $P<0.05$. There were insufficient data on perishable crop interventions for further analysis.

The searchable SQL database was created to facilitate interactive data visualization, given the numerous dimensions of the challenge and the scope of the interventions. The database provides a simple way for users to filter the dataset by data fields such as crop, country and postharvest activity stage for further analysis. Users can also access the bibliographic information and intervention loss datasets for single or multiple studies. The database provides cross-tabulations and a series of graphs.

\section{Data availability}

The data that support the findings of this analysis are available upon request. The bibliographic details of the 334 included studies are listed in Supplementary Table 1, and the searchable database is available at https://PHCeres2030.net/.

\section{Code availability}

The title and abstract deduplication code is available at https://github.com/ MariyaIvanina/ArticlesDeduplicator. Outputs from the model used for machine-processing of titles and abstracts in this Ceres2030 evidence-synthesis study can be provided by J. Porciello (e-mail: jat264@cornell.edu) upon request.

Received: 1 March 2020; Accepted: 8 September 2020; Published online: 12 October 2020

\section{References}

1. World Population Prospects 2019 (UNDESA, 2019).

2. Alexandratos, N. \& Bruinsma, J. World Agriculture Towards 2030/2050: The 2012 Revision ESA Working Paper No. 12-03 (FAO, 2012).

3. FAO, IFAD, UNICEF, WFP \& WHO The State of Food Security and Nutrition in the World 2017: Building Resilience for Peace and Food Security (FAO, 2017); http://www.fao.org/3/a-i7695e.pdf

4. The State of Food Security and Nutrition in the World 2019: Safeguarding Against Economic Slowdowns and Downturns (FAO, 2019); http://www.fao. org/3/ca5162en/ca5162en.pdf

5. World Bank, NRI \& FAO Missing Food: The Case of Postharvest Grain Losses in Sub-Saharan Africa Report No., 60371-AFR (World Bank, 2011); http:// siteresources.worldbank.org/INTARD/Resources/MissingFoods10_web.pdf

6. Hodges, R. J., Buzby, J. C. \& Bennett, B. Postharvest losses and waste in developed and less developed countries: opportunities to improve resource use. J. Agric. Sci. 149, 37-45 (2011)
7. Kitinoja, L., Saran, S., Roy, S. K. \& Kader, A. A. Postharvest technology for developing countries: challenges and opportunities in research, outreach and advocacy. J. Sci. Food Agric. 91, 597-603 (2011).

8. Mutungi, C. \& Affognon, H. Gaps and Outlook for Postharvest Research and Innovation in Ghana Policy Brief No. 4(13) (ICIPE, 2013); http://hdl.handle. net/10625/52221

9. Reducing Global Food Waste and Spoilage: A Rockefeller Foundation Initiative-Assessing Resources Needed and Available to Reduce Postharvest Food Loss in Africa (Global Knowledge Initiative, 2014); https://go.nature. com/33hunKg

10. Mvumi, B. M. \& Stathers, T. E. Food security challenges in sub-Saharan Africa: the potential contribution of postharvest skills, science and technology in closing the gap. In Proc. 11th IWCSPP (eds Arthur, F. H. et al.) 32-43 (Department of Agriculture, Ministry of Agriculture and Cooperatives, 2014).

11. Affognon, H., Mutungi, C., Sanginga, P. \& Borgemeister, C. Unpacking postharvest losses in sub-Saharan Africa: a meta-analysis. World Dev. 66, 49-68 (2015).

12. Hansen, A. R., Keenan, C. \& Sidhu, G. Nutritious Food Foresight: Twelve Ways to Invest in Good Food in Emerging Markets (Global Knowledge Initiative, 2019); https://go.nature.com/2GkRxq1

13. Stathers, T. \& Mvumi, B. M. in Preventing Food Losses and Waste to Achieve Food Security and Sustainability (ed. Yahia, E. M.) Ch. 27 (Burleigh Dodds Science, 2020)

14. United Nations Sustainable Development Goals (United Nations, 2015); https://sustainabledevelopment.un.org/topics/sustainabledevelopmentgoals\#

15. African Union Malabo Declaration on Accelerated Growth and Transformation for Shared Prosperity and Improved Livelihoods (ReSAKSS, IFPRI, 2014); https://go.nature.com/2SdnVO7

16. The State of Food and Agriculture 2019: Moving Forward on Food Loss and Waste Reduction (FAO, 2019); http://www.fao.org/3/ca6030en/ca6030en.pdf

17. Coyne, F. P. Improving the protection of stored maize from insect attack on small farms in Kenya. International Pest Control 8-13 (May/June 1971).

18. Holst, N., Meikle, W. G. \& Markham, R. H. Grain injury models for Prostephanus truncatus (Coleoptera: Bostrichidae) and Sitophilus zeamais (Coleoptera: Curculionidae) in rural maize stores in West Africa. J. Econ. Entomol. 93, 1338-1346 (2000).

19. Caswell, G. H. The development and extension of nonchemical control techniques for stored cowpeas in Nigeria. In Proc. 1st International Working Conference on Stored-Product Entomology (eds Brady, E. U. et al.) 63-67 (1975).

20. Nahdy, M. S. \& Agona, A. Studies on the control of the bean bruchids Acanthoscelides obtectus (Say) and Zabrotes subfasciatus (Boheman) (Coleoptera: Bruchidae) in the East African region CIAT African Workshop Series 27, 50-59 (CIAT, 1992).

21. Turner, P. C. et al. Reduction in exposure to carcinogenic aflatoxins by postharvest intervention measures in west Africa: a community-based intervention study. Lancet 365, 1950-1956 (2005).

22. Palanisami, A., Manickam, A. \& Neelakantan, S. Fungal flora and aflatoxin production in relation to post-harvest practices in groundnut. Madras Agric. J. 1, 26-31 (1990)

23. Xu, Y. et al. Study of an educational hand sorting intervention for reducing aflatoxin $\mathrm{B}_{1}$ in groundnuts in rural Gambia. J. Food Prot. 80 44-49 (2017).

24. Lal, L. Studies on natural repellents against potato tuber moth (Phthorimaea operculella Zeller) in country stores. Potato Res. 2, 329-334 (1987).

25. Giri, Y. P. et al. Efficacy of botanicals and Bacillus thuringiensis to control potato tuber moth, Phthorimaea operculella (Zeller), in potato storage in Nepal. In Proc. 15th Triennial Symposium of the International Society for Tropical Root Crops 163-170 (ISTRC, CIP, Universidad Nacional Agraria La Molina, 2009).

26. Hell, K., Lamboni, Y., Houndekon, T. \& Alidou, G. M. Augmented release of Teretrius nigrescens Lewis (Coleoptera: Histeridae) for the control of Prostephanus truncatus (Horn) (Coleoptera: Bostrichidae) in stored cassava chips. J. Stored Prod. Res. 3, 367-376 (2006).

27. Afolabi, J. F., Akano, D. A. \& Atanda, O. O. The use of termitaria in reducing losses in stored yams. Trop. Sci. 37, 71-74 (1997)

28. Ayemou-Allou, A. S., Tschannen, A., Allou, D. \& Assa, A. Influence of three soil physical parameters on the harvesting of cassava (Manihot esculenta Crantz) in central Cote d'Ivoire. J. Appl. Biosci. 9, 416-423 (2008).

29. Tata-Hangy, K. \& Lutete, D. Observations on the effects of different methods of processing cassava chips on chips damage due to insect attacks during storage. Tropicultura 15, 173-176 (1997).

30. Katundu, M., Hendriks, S., Bower, J. \& Siwela, M. Can sequential harvesting help small holder organic farmers meet consumer expectations for organic potatoes? Food Qual. Prefer. 4, 379-384 (2010).

31. Smit, N. E. J. M. The effect of the indigenous cultural practices of in-ground storage and piecemeal harvesting of sweetpotato on yield and quality losses caused by sweetpotato weevil in Uganda. Agric. Ecosyst. Environ. 64, 191-200 (1997). 
32. Fite, T., Getu, E. \& Sori, W. Integrated management of sweetpotato weevil, Cylas puncticollis (Boheman) (Coleoptera: Curculionidae) in Eastern Ethiopia. J. Entomol. 11, 225-237 (2014).

33. Tomlins, K. I., Ndunguru, G. T., Rwiza, E. \& Westby, J. Influence of pre-harvest curing and mechanical injury on the quality and shelf-life of sweet potato (Ipomoea batatas (L.) Lam) in East Africa. J. Hortic. Sci. Biotechnol. 77, 399-403 (2002).

34. Mozie, O. Evaluation of weight losses and rate of rotting due to mechanical injuries sustained during harvesting of white yam (Dioscorea rotundata) stored in the conventional barn. Trop. Root Tuber Crops Newsl. 12/13, 18-21 (1981/1982)

35. Kuyu, C. G., Yetenayet, B. T. \& Gemechu, G. A. Study on post-harvest quantitative and qualitative losses of potato tubers from two different road access districts of Jimma zone, South West Ethiopia. Heliyon 5, e02272 (2019)

36. Mazhar, M. S., Amin, M., Malik, A. E., Campbell, J. \& Johnson, P. Improved harvest and desapping practices affect mango fruit quality along the supply chains. Int. J. Agric. Biol. 13, 776-780 (2011).

37. Gitonga, Z., de Groote, H. \& Tefera, T. Metal silo grain storage technology and household food security in Kenya. J. Dev. Agric. Econ. 7 222-230 (2015).

38. Mahrouf, A. R. M. \& Rafeek, M. I. M. Mechanization of paddy harvesting: the economic perspective. Ann. Sri Lanka Dep. Agric. 5, 161-172 (2003).

39. Basavarajappa, D. N., Chinnappa, B. \& Sannathimmappa, H. G. Farm machinery: the economics of paddy harvesting. Int. J. Agric. Eng. 6, 240-243 (2013).

40. Alam, M. A., Hossen, A., Islam, A. K. M. S. \& Alam, M. Performance evaluation of power-operated reapers for harvesting rice at farmers' field. J. Bangladesh Agric. Univ. 16, 144-150 (2018).

41. Gitonga, Z. M., de Groote, H., Kassie, M. \& Tefera, T. Impact of metal silos on households' maize storage, storage losses and food security: an application of a propensity score matching. Food Policy 43, 44-55 (2013).

42. Omotilewa, O. J., Ricker-Gilbert, J., Ainembabazi, J. H. \& Shively, G. E. Does improved storage technology promote modern input use and food security? Evidence from a randomized trial in Uganda. J. Dev. Econ. 135, 176-198 (2018).

43. Mwebaze, P. \& Mugisha, J. Adoption, utilisation and economic impacts of improved post-harvest technologies in maize production in Kapchorwa district, Uganda. Int. J. Postharvest Technol. Innov. 2, 301-327 (2011).

44. Chegere, M. J. Post-harvest losses reduction by small-scale maize farmers: the role of handling practices. Food Policy 77, 103-115 (2018).

45. Prasanna, P. H. S. N., Gunaratne, L. H. P. \& Withana, W. D. R. S. Economic analysis of paddy threshing methods. Sri Lankan J. Agric. Econ. 6, 51-66 (2004)

46. Ndegwa, M. K., de Groote, H., Gitonga, Z. M. \& Bruce, A. Y. Effectiveness and economics of hermetic bags for maize storage: results of a randomized controlled trial in Kenya. Crop Prot. 90, 17-26 (2016).

47. Ng'ang'a, J., Mutungi, C., Imathiu, S. M. \& Affognon, H. Low permeability triple-layer plastic bags prevent losses of maize caused by insect in rural on-farm stores. Food Secur. 8, 621-633 (2016).

48. Donnelly, C. A. et al. Four principles to make evidence synthesis more useful for policy. Nature 558, 361-364 (2018).

49. Mvumi, B. M., Giga, D. P. \& Chiuswa, D. V. The maize (Zea mays L.) post-production practices of smallholder farmers in Zimbabwe: findings from surveys. J. Appl. Sci. South. Afr. 1, 115-130 (1995).

50. Stathers, T. E. et al. Do diatomaceous earths have potential as grain protectants for small-holder farmers in sub-Saharan Africa? The case of Tanzania. Crop Prot. 27, 44-70 (2008).

51. Waongo, A., Yamkoulga, M., Dabire-Binso, C. L., Ba, M. N. \& Sanon, A Conservation post-recolte des cereals en zone sud-soudanienne du Burkina Faso: perception paysanne et evaluation des stocks. Int. J. Biol. Chem. Sci. 7 , 1157-1167 (2013).

52. Stathers, T., Lamboll, R. \& Mvumi, B. M. Postharvest agriculture in changing climates: its importance to African smallholder farmers. Food Secur. 5, 361-392 (2013).

53. Abass, A. B. et al. Post-harvest food losses in a maize-based farming system of semi-arid savannah areas of Tanzania. J. Stored Prod. Res. 57, 49-57 (2014)

54. Baoua, I. B. et al. Grain storage and insect pests of stored grain in rural Niger. J. Stored Prod. Res. 64, 8-12 (2015).

55. Glasziou, P. \& Chalmers, I. Research waste is still a scandal-an essay by Paul Glasziou and Iain Chalmers. BMJ 363, k4645 (2018).

56. Bokusheva, R. et al. Factors determining the adoption and impact of a postharvest storage technology. Food Secur. 4, 279-293 (2012).

57. Villane, B. R. T., Shongwe, M. I., Motsa, N. M. \& Shongwe, V. D. Adoption of postharvest technologies used by smallholder farmers in Swaziland. Afr. J. Agric. Res. 7, 4983-4995 (2012).

58. Moussa, B., Abdoulaye, T., Coulibaly, O., Baributsa, D. \& Lowenberg-DeBoer, J. Adoption of on-farm hermetic storage for cowpea in West and Central Africa in 2012. J. Stored Prod. Res. 58, 77-86 (2014).
59. Kitinoja, L. \& Barrett, D. M. Extension of small-scale postharvest horticulture technologies-a model training and services centre. Agriculture 5, 441-455 (2015).

60. Mujuka, E., Mburu, J., Ogutu, A. \& Ambuko, J. Returns to investment in postharvest loss reduction technologies among mango farmers in Embu County, Kenya. Food Energy Secur. 00, e195 (2019).

61. Compton, J. A. F. et al. Reducing losses in small farm grain storage in the tropics. Trop. Sci. 33, 283-318 (1993).

62. Baributsa, D., Lowenberg-DeBoer, J. \& Djibo, A. K. Cell phone videos for communicating hermetic cowpea storage skills. In Proc. 5th World Cowpea Research Conference (eds Boukar, O. et al.) (IITA, 2010).

63. Adegbola, P. Y., Arouna, A. \& Ahoyo, N. R. A. Analyse des facteurs affectant l'adoption des greniers améliorés pour le stockage du maïs au Sud-Bénin. Bull. Rech. Agron. Bénin 2, 43-50 (2011).

64. Baributsa, D. et al. Market building for post-harvest technology through large-scale extension efforts. J. Stored Prod. Res. 58, 59-66 (2014).

65. de Groote, H. et al. Measuring rural consumers' willingness to pay for quality labels using experimental auctions: the case of aflatoxin-free maize in Kenya. Agric. Econ. 47, 33-45 (2015).

66. Kitinoja, L. Innovative small-scale postharvest technologies for reducing losses in horticultural crops. Ethiopian J. Appl. Sci. Technol. 1, 9-15 (2013).

67. Ricker-Gilbert, J. \& Jones, M. Does storage technology affect adoption of improved maize varieties in Africa? Insights from Malawi's input subsidy program. Food Policy 50, 92-100 (2015).

68. Jones, M., Alexander, C., Olynk Widmar, N., Ricker-Gilbert, J. \& Lowenberg-DeBoer, J. M. Do insect and mold damage affect maize prices in Africa? Evidence from Malawi. Mod. Econ. 7, 1168-1185 (2016).

69. Walker, S., Jaime, R., Kagot, V. \& Probst, C. Comparative effects of hermetic and traditional storage devices on maize grain: mycotoxin development, insect infestation and grain quality. J. Stored Prod. Res. 77, 34-44 (2018).

70. Dijkink, B., Broeze, J., Axmann, H. \& Vollebregt, M. Hermetic Bag for the Storage of Maize: Economic Perspective in Different Sub-Saharan African Countries, Food Security and Greenhouse Gas Emissions Working Paper No. 291 (CGIAR Research Program on Climate Change, Agriculture and Food Security, 2019).

71. Govereh, J., Muchetu, R. G., Mvumi, B. M. \& Chuma, T. Analysis of distribution systems for supply of synthetic grain protectants to maize smallholder farmers in Zimbabwe: implications for hermetic grain storage bag distribution. J. Stored Prod. Res. 84, 101520 (2019).

72. Omotilewa, O. J., Ricker-Gilbert, J. \& Ainembabazi, J. H. Subsidies for agricultural technology adoption: evidence from a randomised experiment with improved grain storage bags in Uganda. Am. J. Agric. Econ. 101, 753-772 (2019)

73. Darfour, B. \& Rosentrater, K. A. Cost assessment of five different maize grain handling techniques to reduce postharvest losses from insect contamination. Insects 11, 50 (2020).

74. Landis, J. R. \& Koch, G. C. The measurement of observer agreement for categorical data. Biometrics 33, 159-174 (1977).

75. R Core Team R: A Language and Environment for Statistical Computing $\mathrm{R}$ version 3.5.1 (R Foundation for Statistical Computing, 2018).

76. de Mendiburu, F. agricolae: Statistical procedures for agricultural research. R package version 1.3-1 (2019); https://CRAN.R-project.org/package=agricolae

\section{Acknowledgements}

This systematic analysis of the evidence-base on PHL reduction interventions was conducted without funding. The research team contributed their time to work together virtually on this study outside their main work roles and responsibilities. The Ceres2030 project (funded through the Bill and Melinda Gates Foundation) identified the need for the synthesis of the evidence on PHL reduction interventions, and we thank J. Porciello of Cornell University for supporting the research team with advice. The Ceres2030 project covered travel and accommodation costs for six of the team members to join an inception meeting in June 2019. We thank the PHL reduction community of researchers and the stakeholders they have worked with for their study of different interventions, which provided the content for this analysis. We also thank the network of libraries for providing the literature.

\section{Author contributions}

All authors contributed to the conceptualization of the study and development of the protocol and coding framework. M.K. and J.A. implemented the literature search strategy and obtained full-text versions of the required studies. A.E. designed and programmed the interactive database to fit the coding framework. The title/abstract screening, full-text screening and data extraction were done by the following authors (with the number of studies for which each author did each task listed in parentheses): T.S. $(6,089,421,132)$, D.H. $(7,739,500,100)$, L.K. $(4,830,578,62)$, B.M.M. $(1,925,151$, $12)$, O.O. $(3,805,138,10)$, A.E. $(1,653,0,8)$ and M.T. $(0,0,10)$. T.S. and D.H. cleaned, analysed and synthesized the extracted data. T.S. led the writing of the manuscript. 
D.H. covered the results for perishable crops and handling practices and costs. All authors contributed comments and provided critical feedback using their specific expertise at several stages to shape the analysis and write the manuscript. The final draft benefited from notable further editing by M.T. to improve its flow and succinctness. A.E. processed and visualized the data in the database (including all the programming) with input from T.S. and D.H.

\section{Competing interests}

The authors declare no competing interests.

\section{Additional information}

Extended data is available for this paper at https://doi.org/10.1038/s41893-020-00622-1.

Supplementary information is available for this paper at https://doi.org/10.1038/ s41893-020-00622-1.

Correspondence and requests for materials should be addressed to T.S.
Reprints and permissions information is available at www.nature.com/reprints.

Publisher's note Springer Nature remains neutral with regard to jurisdictional claims in published maps and institutional affiliations.

(c) (i) Open Access This article is licensed under a Creative Commons

Attribution 4.0 International License, which permits use, sharing, adaptation, distribution and reproduction in any medium or format, as long as you give appropriate credit to the original author(s) and the source, provide a link to the Creative Commons license, and indicate if changes were made. The images or other third party material in this article are included in the article's Creative Commons license, unless indicated otherwise in a credit line to the material. If material is not included in the article's Creative Commons license and your intended use is not permitted by statutory regulation or exceeds the permitted use, you will need to obtain permission directly from the copyright holder. To view a copy of this license, visit http://creativecommons. org/licenses/by/4.0/.

(c) The Author(s) 2020 
Interventions for crop postharvest loss reduction in food systems in sub-Saharan Africa and South Asia

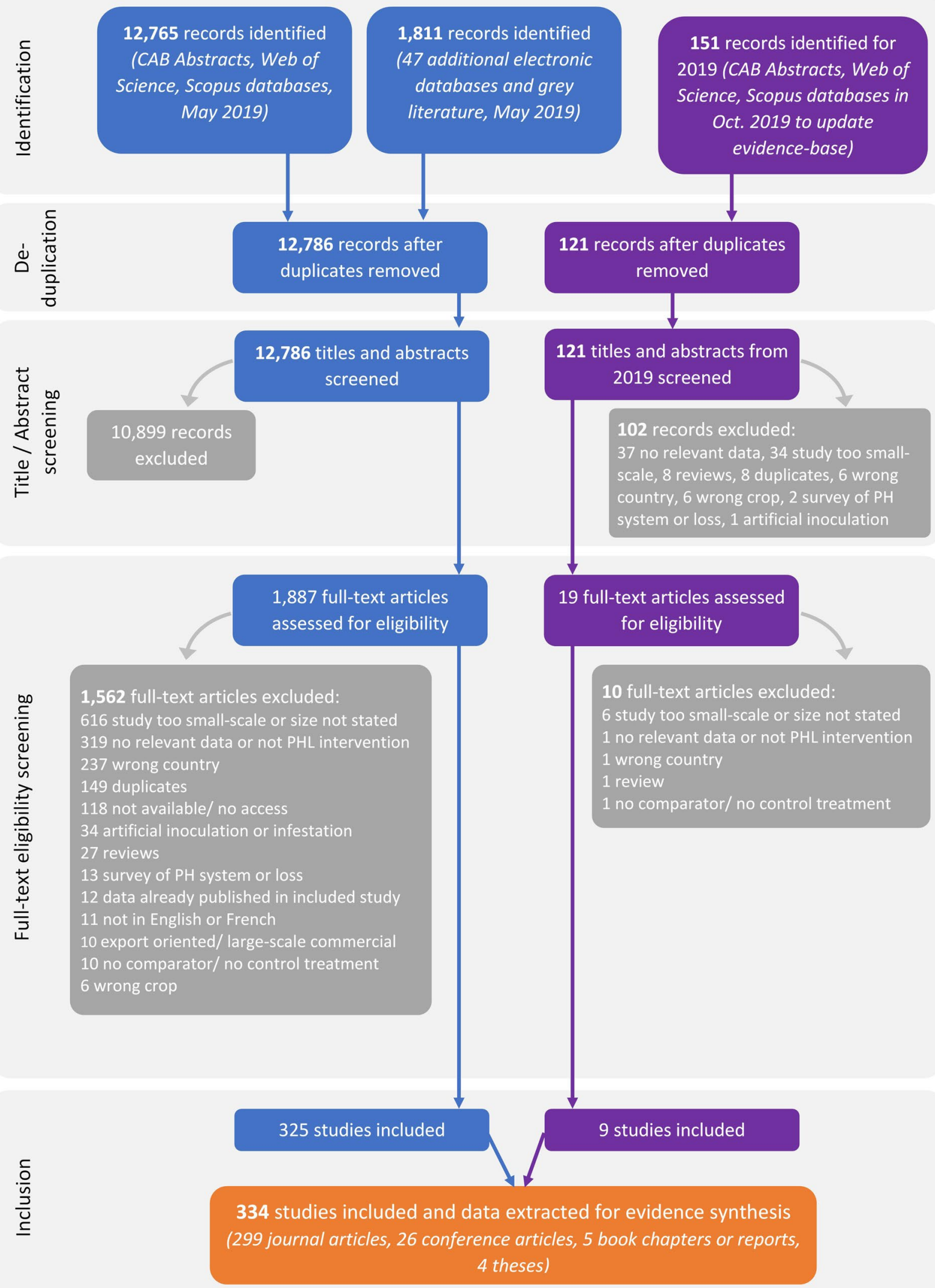

Extended Data Fig. 1| PRISMA Flowchart. The number of articles that were retrieved in the searches and passed each subsequent stage of screening is shown. 


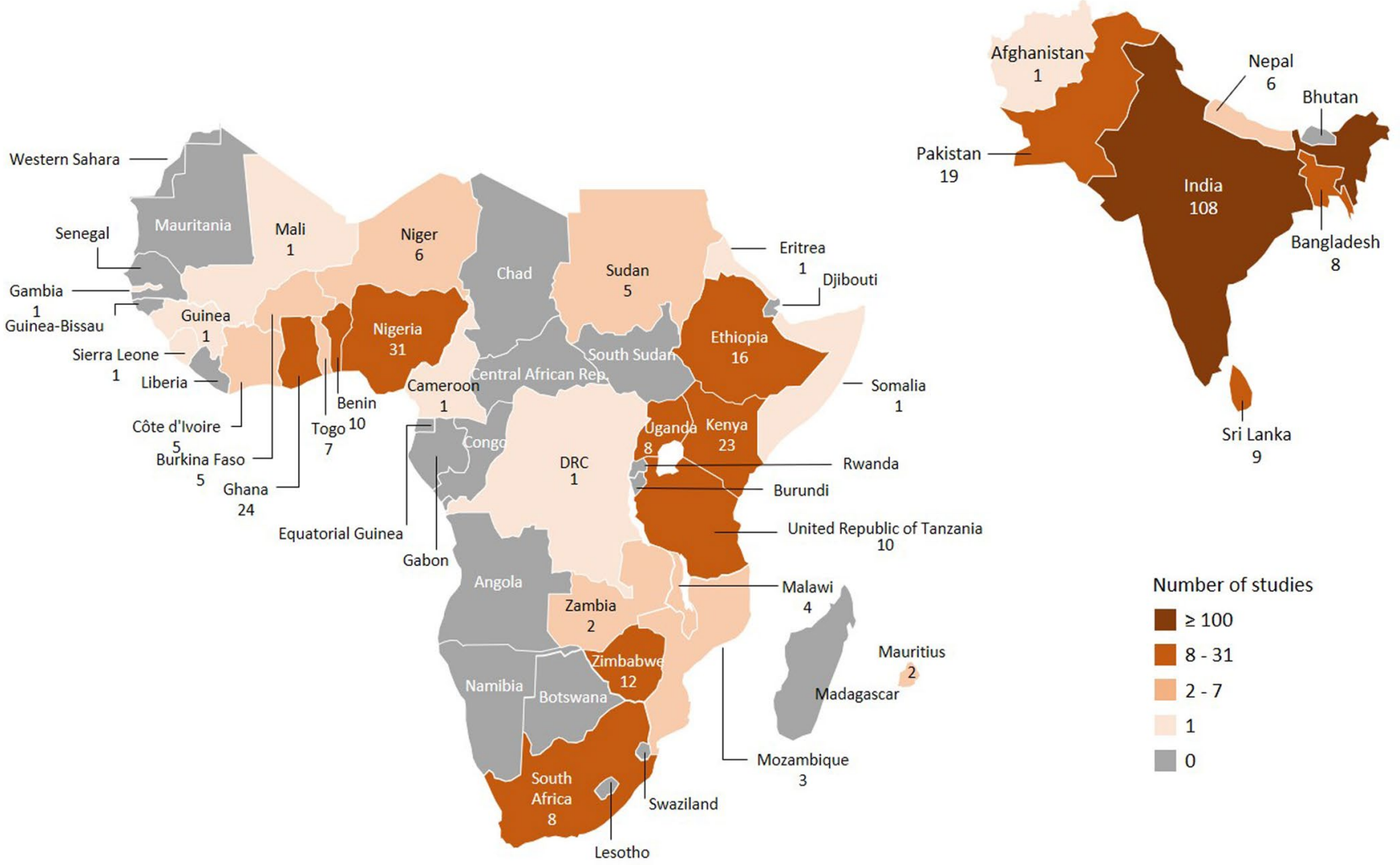

Extended Data Fig. 2 | Distribution of studies. The 334 included postharvest loss reduction intervention studies are shown by country. 
a

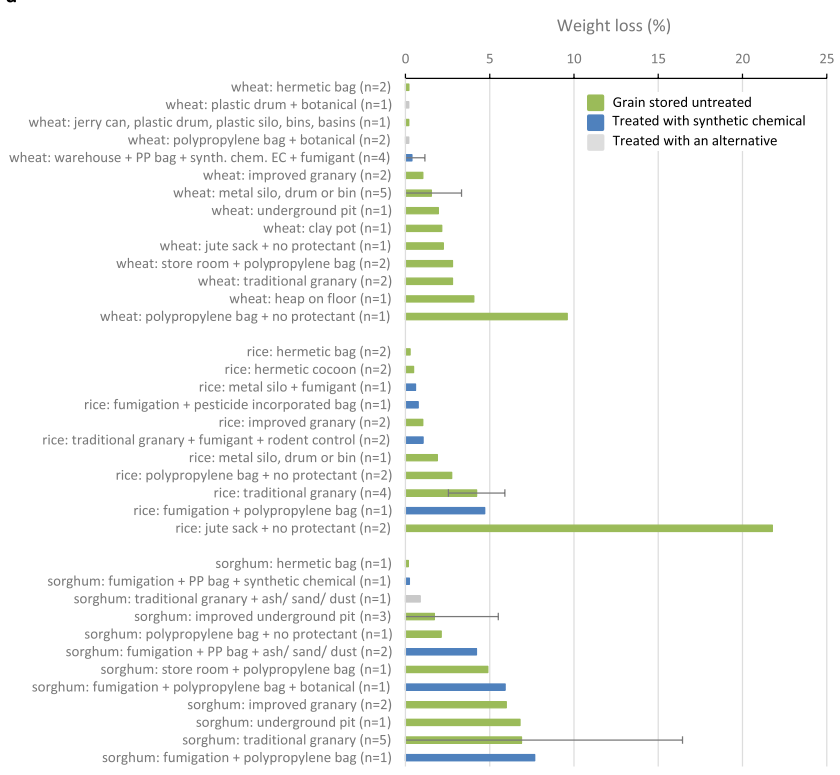

b

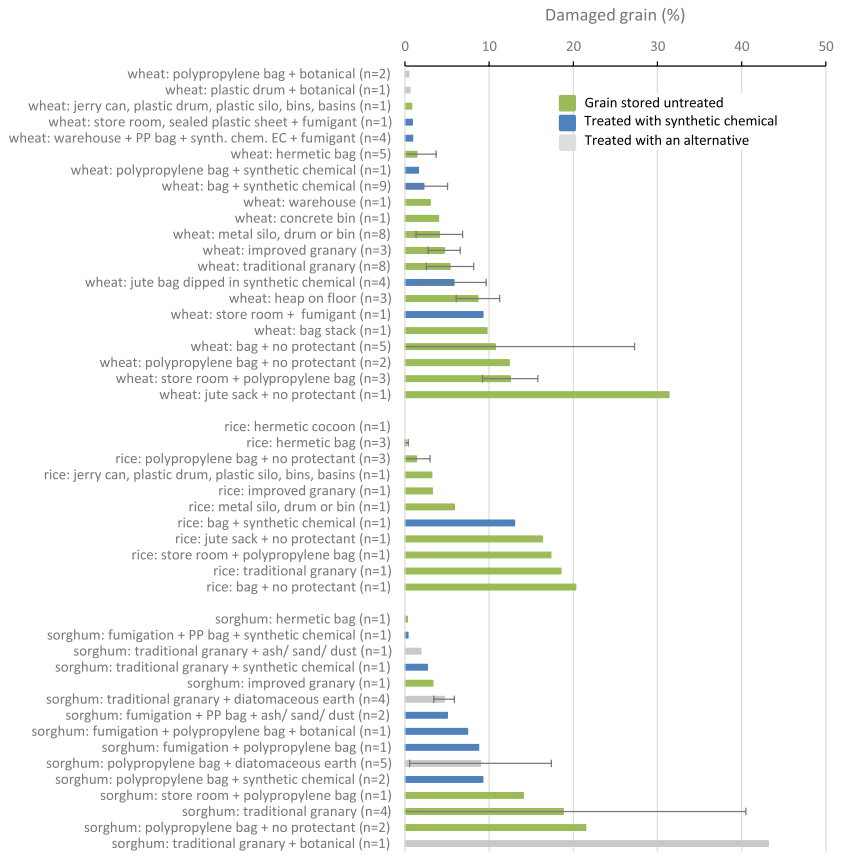

Extended Data Fig. 3 | Comparative losses in quantity and quality of stored wheat, rice and sorghum. a,b, Quantity (\% weight loss) (a) and quality (\% damaged grain) (b) loss of wheat, rice and sorghum stored for 6 months using different storage interventions. Data for the three crops are shown separately with the interventions sorted in order of efficacy for each crop. The means, $95 \%$ confidence intervals $(\mathrm{Cl})$ and $n$ values (that is, the number of times this intervention was found in the 334 studies) are presented. The loss levels are dependent on numerous factors including the conditions during the study, which can result in high heterogeneity between studies. The loss levels for each intervention need to be interpreted with caution particularly where the $n$ value is low. Interventions in which the grain was stored untreated are shown as green bars. The blue bars indicate grain treated with a synthetic chemical. The grey bars indicate grain treated with an alternative method. $\mathrm{EC}=$ emulsifiable concentrate, $\mathrm{PP}$ bag $=$ polypropylene bag. 


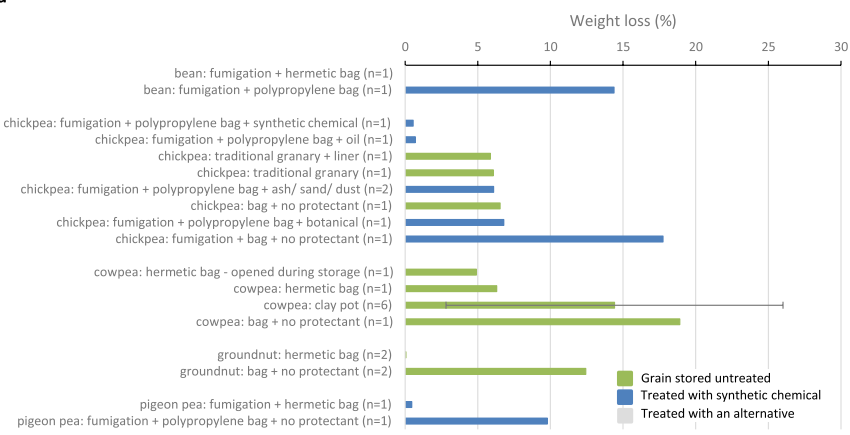

b

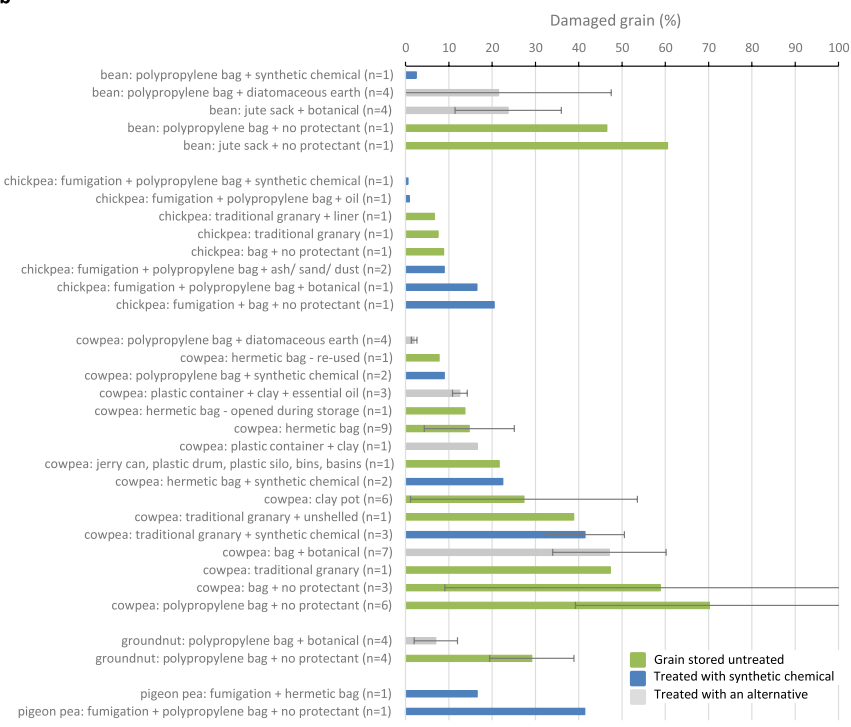

Extended Data Fig. 4 | Comparative losses in quantity and quality of stored legumes. a,b, Quantity (\% weight loss) (a) and quality (\% damaged grain) (b) loss of beans, chickpeas, cowpeas, groundnuts and pigeon peas stored for 4.5 months using different storage interventions. Data for the five crops are shown separately with the interventions sorted in order of efficacy for each crop. The means, $95 \%$ confidence intervals $(\mathrm{Cl})$ and $n$ values (that is, the number of times this intervention was found in the 334 studies) are presented. The loss levels are dependent on numerous factors including the conditions during the study, which can result in high heterogeneity between studies. The loss levels for each intervention need to be interpreted with caution particularly where the $n$ value is low. Interventions in which the grain was stored untreated are shown as green bars. The blue bars indicate grain treated with a synthetic chemical. The grey bars indicate grain treated with an alternative method. 